\title{
Correlation between spatial (3D) structure of pea and bean thylakoid membranes and arrangement of chlorophyll-protein complexes
}

Izabela Rumak', Radosław Mazur², Katarzyna Gieczewska', Joanna Kozioł-Lipińska', Borys Kierdaszuk, Wojtek P. Michalski ${ }^{4}$, Brian J. Shiell ${ }^{4}$, Jan Henk Venema ${ }^{5}$, Wim J. Vredenberg ${ }^{6}$,

Agnieszka Mostowska ${ }^{1}$ and Maciej Garstka ${ }^{2 *}$

\begin{abstract}
Background: The thylakoid system in plant chloroplasts is organized into two distinct domains: grana arranged in stacks of appressed membranes and non-appressed membranes consisting of stroma thylakoids and margins of granal stacks. It is argued that the reason for the development of appressed membranes in plants is that their photosynthetic apparatus need to cope with and survive ever-changing environmental conditions. It is not known however, why different plant species have different arrangements of grana within their chloroplasts. It is important to elucidate whether a different arrangement and distribution of appressed and non-appressed thylakoids in chloroplasts are linked with different qualitative and/or quantitative organization of chlorophyll-protein (CP) complexes in the thylakoid membranes and whether this arrangement influences the photosynthetic efficiency.

Results: Our results from TEM and in situ CLSM strongly indicate the existence of different arrangements of pea and bean thylakoid membranes. In pea, larger appressed thylakoids are regularly arranged within chloroplasts as uniformly distributed red fluorescent bodies, while irregular appressed thylakoid membranes within bean chloroplasts correspond to smaller and less distinguished fluorescent areas in CLSM images. 3D models of pea chloroplasts show a distinct spatial separation of stacked thylakoids from stromal spaces whereas spatial division of stroma and thylakoid areas in bean chloroplasts are more complex. Structural differences influenced the PSII photochemistry, however without significant changes in photosynthetic efficiency. Qualitative and quantitative analysis of chlorophyll-protein complexes as well as spectroscopic investigations indicated a similar proportion between PSI and PSII core complexes in pea and bean thylakoids, but higher abundance of LHCII antenna in pea ones. Furthermore, distinct differences in size and arrangements of LHCII-PSII and LHCI-PSI supercomplexes between species are suggested.
\end{abstract}

Conclusions: Based on proteomic and spectroscopic investigations we postulate that the differences in the chloroplast structure between the analyzed species are a consequence of quantitative proportions between the individual CP complexes and its arrangement inside membranes. Such a structure of membranes induced the formation of large stacked domains in pea, or smaller heterogeneous regions in bean thylakoids. Presented 3D models of chloroplasts showed that stacked areas are noticeably irregular with variable thickness, merging with each other and not always parallel to each other.

\footnotetext{
* Correspondence: garstka@biol.uw.edu.pl

${ }^{2}$ Department of Metabolic Regulation, Institute of Biochemistry, Faculty of Biology, University of Warsaw, Miecznikowa 1, Warsaw, PL-02-096, Poland Full list of author information is available at the end of the article
} 


\section{Background}

The thylakoid system in plants is organized into two distinct domains: grana arranged in stacks of appressed membranes and non-appressed membranes consisting of stroma thylakoids and margins of granal stacks [1]. It is known that appressed membranes that form grana are not essential for photosynthesis but they are ubiquitous in all chlorophyll (Chl) $b$-containing higher plants [1,2]. Many photosynthetic organisms such as red algae, Cyanobacteria, many green algae such as Chlamydomonas reinhardtii have no stacked thylakoids. Apart from higher plants only Charophyta have appressed membranes indistinguishable from those of land plants [1].

Why did plants develop grana? The development of appressed membranes caused structural heterogeneity that is reflected by functional differentiation with respect to the location of hierarchically organized photosyntetic complexes in supercomplexes and megacomplexes within appressed and non-appressed membranes [3,4]. Size and charge differences between PSI and PSII play a key role in their lateral arrangement $[5,6]$. Photosynthetic unit PSII $\alpha$, i.e., LHCII-PSII supercomplex occurs exclusively in appressed regions and is composed of the dimer of the PSII core, minor light-harvesting complexes (Lhcb4-6) and variable amounts of LHCII trimers (Lhcb1-3) [4,7-9]. In non-appressed thylakoid regions the monomeric PSI core complex with four LHCI subunits (Lhca1-4) and with temporarily bound LHCII complex form LHCI-PSI supercomplexes $[7,10]$. In addition the photosynthetic unit PSII $\beta$, i.e. monomeric PSII without LHCII trimers, exists in stroma thylakoids [4,7]. The structural and organizational changes of grana stacks are driven by physical and chemical forces. It is believed that membrane appression is maintained primarily by the balance between the van der Waals attraction versus electrostatic and hydratation repulsion [6].

It is argued that the reason for the development of appressed membranes in plants is that their photosynthetic apparatus needs to cope with and survive ever-changing environmental conditions, such as transition from darkness, low-light to high-light conditions [1] or temperature fluctuation [11,12]. Shortterm changes are due to the redistribution of absorbed excitation energy (state to state transition) that is based on migration of LHCII from PSII after its phosphorylation [13-15]. Tightly appressed arrangement of thylakoid membranes results in high stability of the chloroplast structure, which needs to be somehow combined with high flexibility/adaptability to dynamically changing environmental conditions [6].

Why do different plant species have different arrangements of grana within their chloroplasts? Examinations of mutants yielded some information on the arrangement of thylakoid membranes within chloroplasts. For example it is known that Arabidopsis Aba mutants - deficient in epoxy-carotenoids - have significantly more grana stacks per chloroplast and more chloroplasts per cell but reduced thylakoid stacking in comparison with wild Arabidopsis plants [16]. In tobacco knockdown of PsbP protein, one of the three oxygen evolving complex proteins in plants, impairs the accumulation of PSII supercomplexes in tobacco and causes large disorder in the thylakoid grana stacking [17]. Studies of the arrangements of thylakoid membranes gave information on chlorophyll $b$-less Arabidopsis mutants. Markedly decreased level or the absence of most of Lhcbs caused fewer grana and much longer stromal thylakoids than in the wild type which implied that the total granal cross-sectional area per chloroplast area was decreased dramatically [18]. Ruban and coworkers [19] argued that in the absence of one of the PSII supercomplex main components, another antenna protein may be recruited to replace a mutated or absent protein, therefore allowing the main complex to assemble and function correctly.

Mutations in the photosynthetic apparatus that cause changes in the thylakoid arrangement give an altered picture of chloroplast thylakoid membranes with profound effect on the photosynthetic efficiency and capacity [18]. Data on the thylakoid arrangement in chloroplasts of different plant species grown in natural or varying environmental conditions, can supplement information obtained for the mutants. Thus answering a question whether and how structural heterogeneity at different levels of thylakoid organization can relate to adaptation/acclimation to changing environment and better photosynthetic efficiency is of significant importance.

In this paper we propose possible interpretation at molecular level of different arrangements of the thylakoid membranes of pea (Pisum sativum L.) and bean (Phaseolus vulgaris L.) grown under similar controlled conditions, as a continuation of our previous studies $[11,12]$. Here we compared different chloroplast structures by confocal laser scanning microscopy (CLSM) followed by computer modeling and by transmission electron microscopy (TEM). The arrangement and composition of chlorophyll-protein (CP) complexes were examined by mild-denaturing electrophoresis, SDS-PAGE, tandem mass spectrometry (MS/MS), immunodetection and by low-temperature steady-state spectrophotometry. Additionally PSII activity was analyzed by modulated and transient Chl $a$ fluorescence.

By applying these diverse methodologies we attempted to describe the relationship between spatial chloroplast structure detected by CLSM in situ and the arrangements of CP complexes within the thylakoid membranes. Our aim was to determine at the molecular level, whether different arrangement and distribution of 
appressed and non-appressed thylakoids in chloroplasts are linked with different qualitative and/or quantitative organization of CP complexes in the thylakoid membranes and whether it influences the photosynthetic efficiency.

\section{Results}

CLSM images and three dimensional (3D) reconstruction of chloroplast structure

CLSM images revealed fluorescent red spots of about $0.5 \mu \mathrm{m}$ separated from one another by dark spaces inside pea chloroplasts (Figure 1A). As it was demonstrated by others [20-22] these bright spots reflected mainly appressed thylakoid membranes containing LHCII-PSII supercomplexes and LHCII trimers rather than nonappressed thylakoids containing PSI. In bean chloroplasts (Figure 1B) smaller and less distinguished fluorescent discs were observed (Figure 1A, B).

Large number (94-116) of fluorescence images were taken in different focal depths. This allowed creating computer-generated 3D structures in which the spatial layout of Chl fluorescence was shown (Figure 1C - F). In pea chloroplasts, the spatial layout of Chl fluorescence consisted of distinguished sharply falling down edges forming deep, curved gorges corresponding to the dark areas in CLSM images (Figure 1C, E). The surface of Chl fluorescence areas is seen in the face view as well as in the side view. 3D images of bean chloroplasts were less regular, with edges not as sharp as in pea, resulting in shallow, irregular caves corresponding to the dark, non-fluorescent areas between the red bodies observed by CLSM (Figure 1D, F). In each 3D structure one can find a corresponding detail of the CLSM image. For a better view of chloroplast 3D structures, animated models are included in Additional file 1: Video S1 and Additional file 2: Video S2. The 3D structures reflect the distribution of Chl fluorescence in a chloroplast as a whole.

\section{TEM chloroplast structure in mesophyll cells}

Images of pea chloroplasts of leaf mesophyll from TEM showed large appressed thylakoid regions (grana), clearly separated from one another by non-appressed ones and oriented paralelly to one another (Figure 2A). These large appressed thylakoids in pea chloroplasts (Figure 2B) correspond to large, uniformly distributed red fluorescent $0.5 \mu \mathrm{m}$ bodies seen by CLSM (cf. Figure 1A). Bean chloroplasts contain numerous non-appressed thylakoid regions with some appressed ones which are smaller than those in pea thylakoids and are irregularly distributed within chloroplasts (Figure 2D, E). These appressed regions in TEM images of bean chloroplasts are counterparts of smaller and less distinguished fluorescent areas seen by CLSM (cf. Figure 1B).

The average value of the ratio of the length of grana thylakoids to the length of stroma thylakoids was

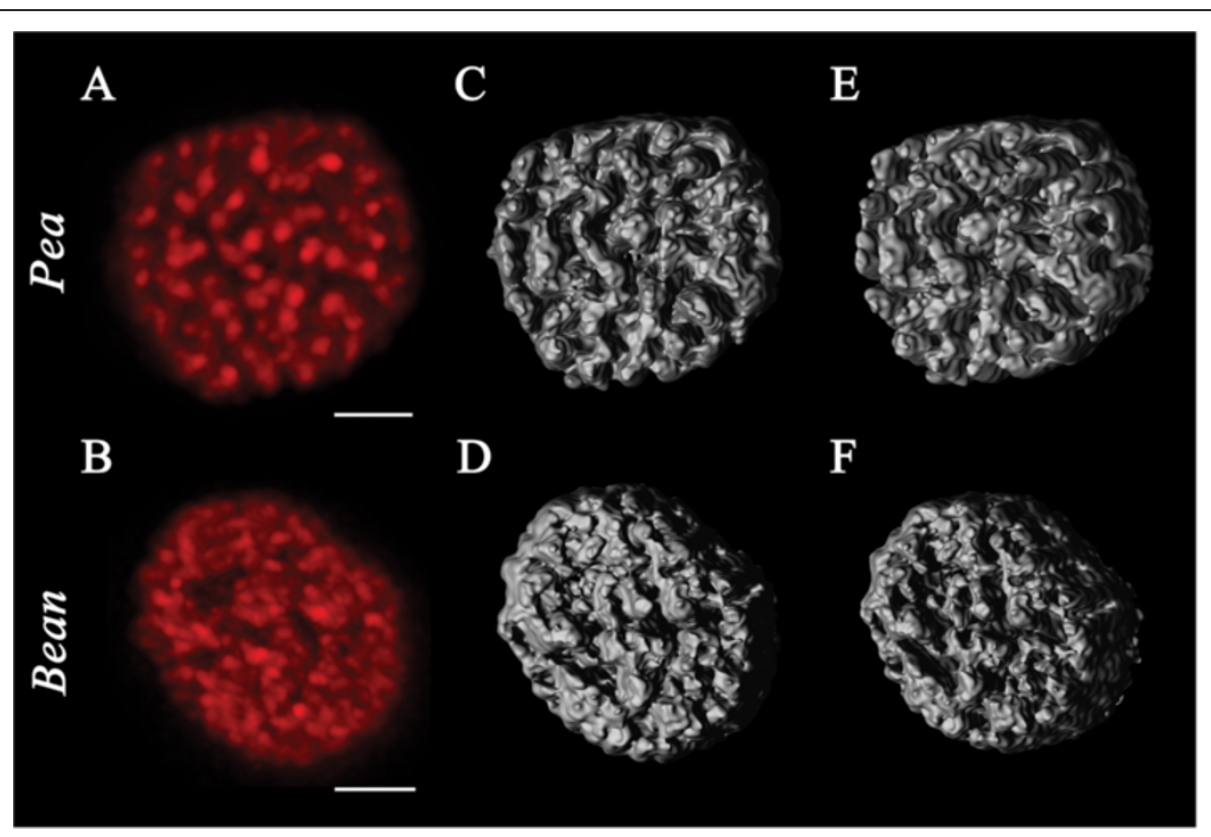

Figure 1 Chlorophyll fluorescence of intact chloroplasts revealed by CLSM and 3D reconstruction of chloroplast structure. The intact chloroplasts of pea (A) and bean (B) were incubated in isoosmotic medium containing $15 \mathrm{mM} \mathrm{NaCl}$ and $4 \mathrm{mM} \mathrm{MgCl}_{2}$. Each red image presents the maximum intensity projection of deconvolved stack of CLSM images. Bar $=2 \mu \mathrm{m}$. Images are representative for at least 20 independent experiments. Grey images represent 3D models of intact pea $(\mathbf{C}, \mathbf{E})$ and bean chloroplasts $(\mathbf{D}, \mathbf{F})$ created after deconvolution. Face $(\mathbf{C}, \mathbf{D})$ and side view $(\mathbf{E}, \mathbf{F})$ of 3D chloroplast models is shown. Each image is a representative of at least 10 independent experiments. 


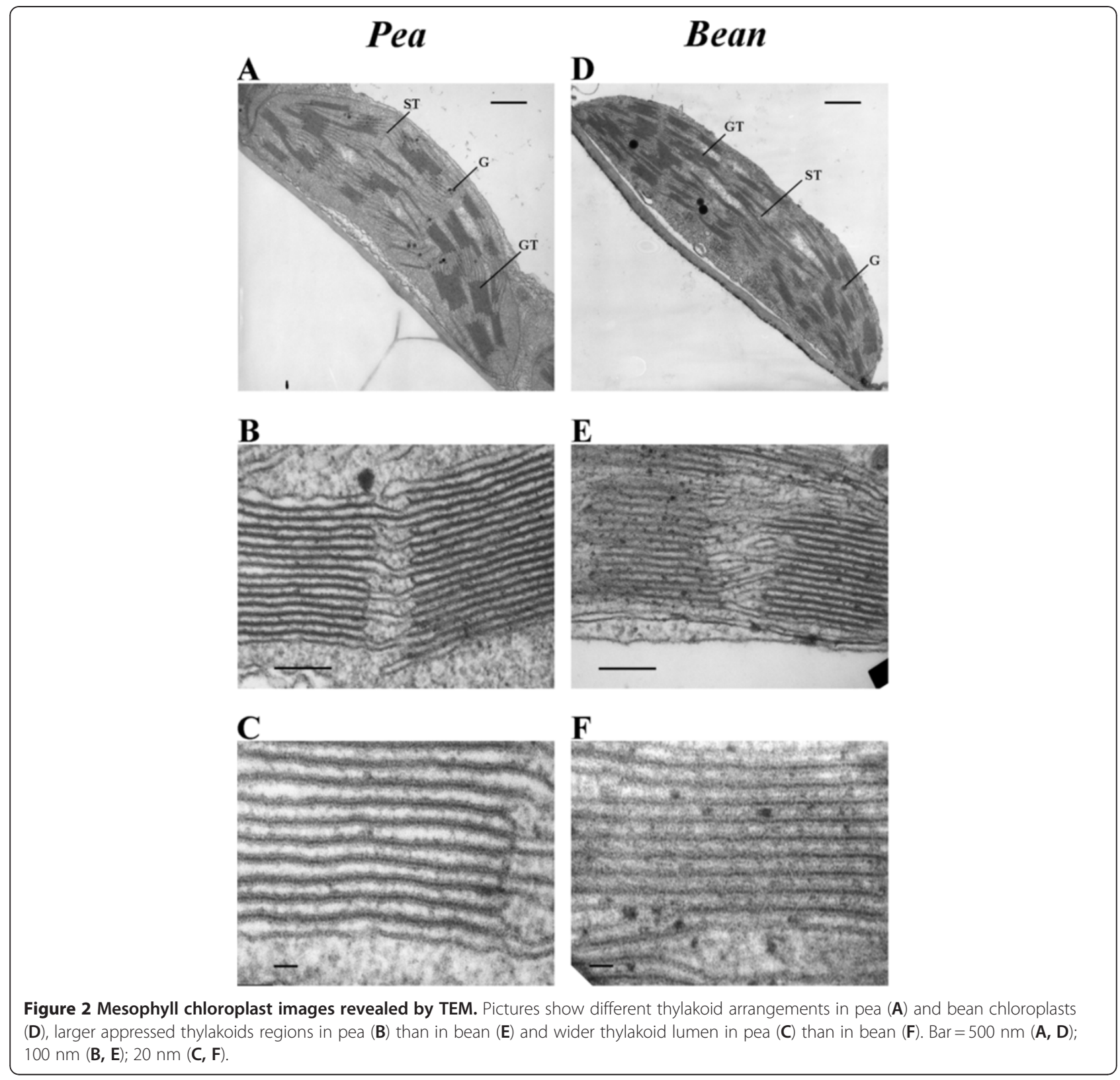

$3.73 \pm 0.24$ in pea while in bean it was only $2.77 \pm 0.18$. The average height ratio of a granum to the number of thylakoids in a particular granum was also bigger in pea (Figure 2B) than in bean chloroplasts (Figure 2E). The distance between the pairs of membranes in thylakoids was estimated to be $20.45 \pm 0.68 \mathrm{~nm}$ in pea and $15.63 \pm 1.57 \mathrm{~nm}$ in bean chloroplasts. This reflected a relatively larger thylakoid lumen in pea thylakoids (Figure 2C) compared with bean thylakoids (Figure 2F). The chloroplast images from intact chloroplasts by CLSM and from leaf tissue in situ by TEM were consistent with each other and gave similar information regarding different distribution and appearance of appressed and nonappressed thylakoids in pea and bean chloroplasts.

\section{Protein composition}

Separation of thylakoid membrane components by SDSPAGE in linear gradient gels (14-20 \%) resulted in a very high resolution of individual proteins from both pea and bean. More than 50 proteins from 10 to $180 \mathrm{kD}$ in molecular weight were distinguishable (Additional file 3: Figure S1). The thylakoid membrane proteins in 15-45 kD molecular weight range are presented in Figure 3. Following electrophoretic separation the proteins of interest were identified by immunodetection and MS/MS analysis.

Electrophoretic pattern was similar in pea and bean thylakoid samples and proteins PsbA, PsbB, PsbC, PsbD, PsbO, Lhca1-4 and Lhcb1-6 were identified in both 


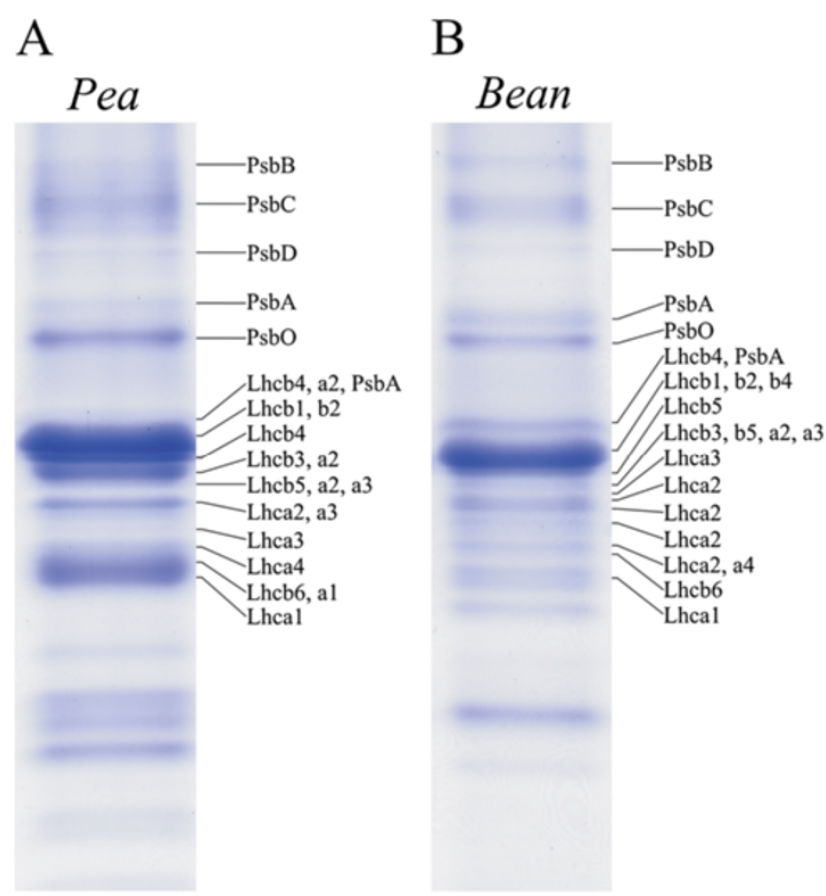

\begin{tabular}{lcc} 
C & \\
Protein & \multicolumn{2}{c}{ Molecular weight [kDa] } \\
\cline { 2 - 3 } name & Pea & Bean \\
\hline Lhcal & 22.1 & 22.0 \\
& 21.5 & \\
\hline Lhca2 & 28.8 & 25.8 \\
& 25.6 & 24.9 \\
& 24.6 & 24.2 \\
& 23.5 & 24.6 \\
& & 24.1 \\
\hline Lhca3 & 24.6 & 25.8 \\
& 23.5 & 24.9 \\
\hline Lhca4 & 22.8 & 23.3 \\
\hline Lhcb1 & 27.1 & 26.6 \\
\hline Lhcb2 & 26.4 & 26.6 \\
\hline Lhcb3 & 25.6 & 25.8 \\
\hline Lhcb4 & 28.8 & 29.0 \\
\hline Lhcb5 & 26.1 & 26.6 \\
\hline Lhcb6 & 22.1 & 26.1 \\
\hline
\end{tabular}

Figure 3 Protein analysis of pea and bean thylakoid membranes. SDS-PAGE resolution of thylakoid membrane proteins ( $9 \mu \mathrm{g}$ of chlorophyll) and visualized by staining with Coomassie Blue R-250 (A, B). Separated bands were analyzed by immunodetection and identified by mass spectrometry. Molecular weights [kD] of pea and bean Lhca1-4 and Lhcb1-6 are given in the table (C).

samples (Figure 3A, B). However significant compositional differences were observed in the gel area where the antennae proteins (Lhca and Lhcb) were localized $(20-30 \mathrm{kD})$. Ten bands in pea (Figure $3 \mathrm{~A})$ and 12 bands in bean samples (Figure 3B) were distinguished in this region. Moreover, pea and bean Lhca1, Lhca2, Lhca3, Lhcb4 and Lhcb5 polypeptides were found in several bands (Figure 3A, B). The main qualitative differences between the pea and bean antennae proteins concern a number of isoforms of Lhca1-3 and their molecular weights (Figure 3C).

The relative amounts of PSII and PSI antennae and the core proteins compared to the total Chl $(a+b)$ amount were determined by immunodetection with specific antibodies (Figure 4). For more accurate estimation each sample was examined at four different chlorophyll concentrations (Figure 4). Quantitative relationships between the two samples were expressed as a ratio of pixel intensities corresponding to selected proteins bands normalized to chlorophyll content. Lhcb1 was detected as one major band in pea and one major and two minor bands in bean samples. The presence of these two additional bands in bean sample is probably an effect of anti- Lhcb1 antibody cross interactivity with the Lhcb4 (top band) and the Lhcb3 (bottom band) proteins (cf. Figure 3B). Because of apparent low antibody specificity against bean Lhcb1, quantitative analysis was performed only for the major band which was about $30 \%$ more abundant in bean than in pea. On the other hand the level of PsbA in bean was about two times higher than in pea, which suggests a higher ratio of Lhcb1 to PsbA in pea thylakoids. The Lhcal detection pattern consisted of one dominant and three (pea) or six (bean) minor bands with higher molecular weight. These additional bands may correspond to different isoforms of Lhca1 [23], (Figure 3). There was no difference between the levels of Lhca1 main band in pea and bean samples but pea/bean ratio for all detected Lhcal bands indicated lower contents in pea, which can be explained by a difference in detected isoforms. PsaA, the PSI core protein, was detected as $55-60 \mathrm{kD}$ band whereas expected molecular weight for this protein is around $83 \mathrm{kD}$ [24]. The PsaA level in pea thylakoids is similar to bean up to the standard deviation.

The $\mathrm{Chl} a / \mathrm{Chl} b$ ratios were the same in pea and bean thylakoids (Figure 4), hence the detected differences in antenna/core protein ratios are likely to be related to protein proportion within the thylakoid membranes. Comparison of Lhcal and PsaA ratios suggests that the amounts of LHCI-PSI were similar in the thylakoids of both species. Due to statistically significant difference in Lhcb1 and PsbA ratios we can explicitly conclude that the proportion of PSII antennae to the core proteins was higher in pea than in bean thylakoids. However 
unambiguous estimation of PSII-LHCII abundance was more complicated because: (i) part of LHCII might be arranged in an aggregated form, (ii) from two up to six LHCII trimers might be associated with a PSII dimer and (iii) PsbA protein is partially localized in PSII monomers which are not connected to LHCII antennae [4,7]. Therefore the mild-denaturing electrophoresis and $77 \mathrm{~K}$ fluorescence spectra were performed for detail analysis.

\section{The chlorophyll-protein complexes composition}

The chlorophyll-protein complexes were gently released from the membranes by $n$-decyl- $\beta$ - $D$-maltopyranoside and n-octyl- $\beta$-D-glucopyranoside, and separated by mild-denaturing 'green' gel electrophoresis. The separation of pea and bean thylakoids revealed 10 green bands assigned to ten different $\mathrm{CP}$ complexes (CP1-CP10) (Figure 5A). According to Allen and Staehelin [25], CP1-CP5 bands correspond to LHCI-PSI and LHCII-PSII supercomplexes. CP6 corresponds to reaction center complexes and includes PSI and PSII complexes without external antennae system attached. Band CP7 is assigned to LHCII supercomplexes. CP8CP10 bands correspond to monomers (Figure 5A). The pea and bean complexes differed in the electrophoretic mobility of their components, especially of CP7 to CP10 that appeared to have higher molecular weights in pea thylakoids.

Immunodetection analysis of PsbD (also named D2), PsaA, Lhcb1-5 and Lhca1-4 proteins with specific antibodies was performed to study the polypeptide composition of the chlorophyll-protein complexes (Figure 5B). Generally all those proteins, except for Lhcb3, Lhcb4, Lhcb5, were found in pea and bean thylakoids in $\mathrm{CP} 1$ to $\mathrm{CP} 4$ bands (Figure 5A). It supports statement that the CP1-CP4 bands could contain LHCI-PSI and LHCII-PSII supercomplexes. Immunodetection of D2, PsaA, Lhca1, Lhca4 within pea CP5 band was low and even lower in bean CP5. In the CP6 band D2, PsaA and Lhcb2 were detected in pea but only D2 in bean. In CP7 mainly Lhcb1 and Lhcb2 were detected in pea and bean; and it is well known that these two proteins build functional LHCII supercomplexes. In this band a weak detection of D2, PsaA, Lhca3 in pea and D2 and Lhca1 in bean was observed. In the monomer region (CP8-CP10) many of individual proteins were resolved.

Quantitative analysis of mild-denaturing electrophoresis pattern showed significant differences in chlorophyll-protein complexes isolated from pea and bean leaves. The amount of CP2 and CP3 containing LHCIPSI and LHCII-PSII supercomplexes was considerably lower in pea than in bean thylakoids (Figure 5C). Moreover, the proportion of CP7 assigned to LHCII complexes was higher in pea than in bean (Figure 5C). Because the mild-denaturing electrophoresis did not preserve completely the $\mathrm{CP}$ supercomplexes structure [25], the presented results illustrate the stability of distinct $\mathrm{CP}$ complexes after the detergent treatment rather than its native organization in thylakoid membranes. Thus, the intensity of CP7 bands (Figure 5A) is related to LHCII associated loosely or strongly with LHCIIPSII supercomplexes and also with LHCII which is not directly associated with PSII. Thus this indicates again that the intensities of $\mathrm{CP} 2$ and CP3 bands (Figure 5A) are a consequence of its stability, probably due to restricted detergent accessibility to the $\mathrm{CP}$ complexes. 


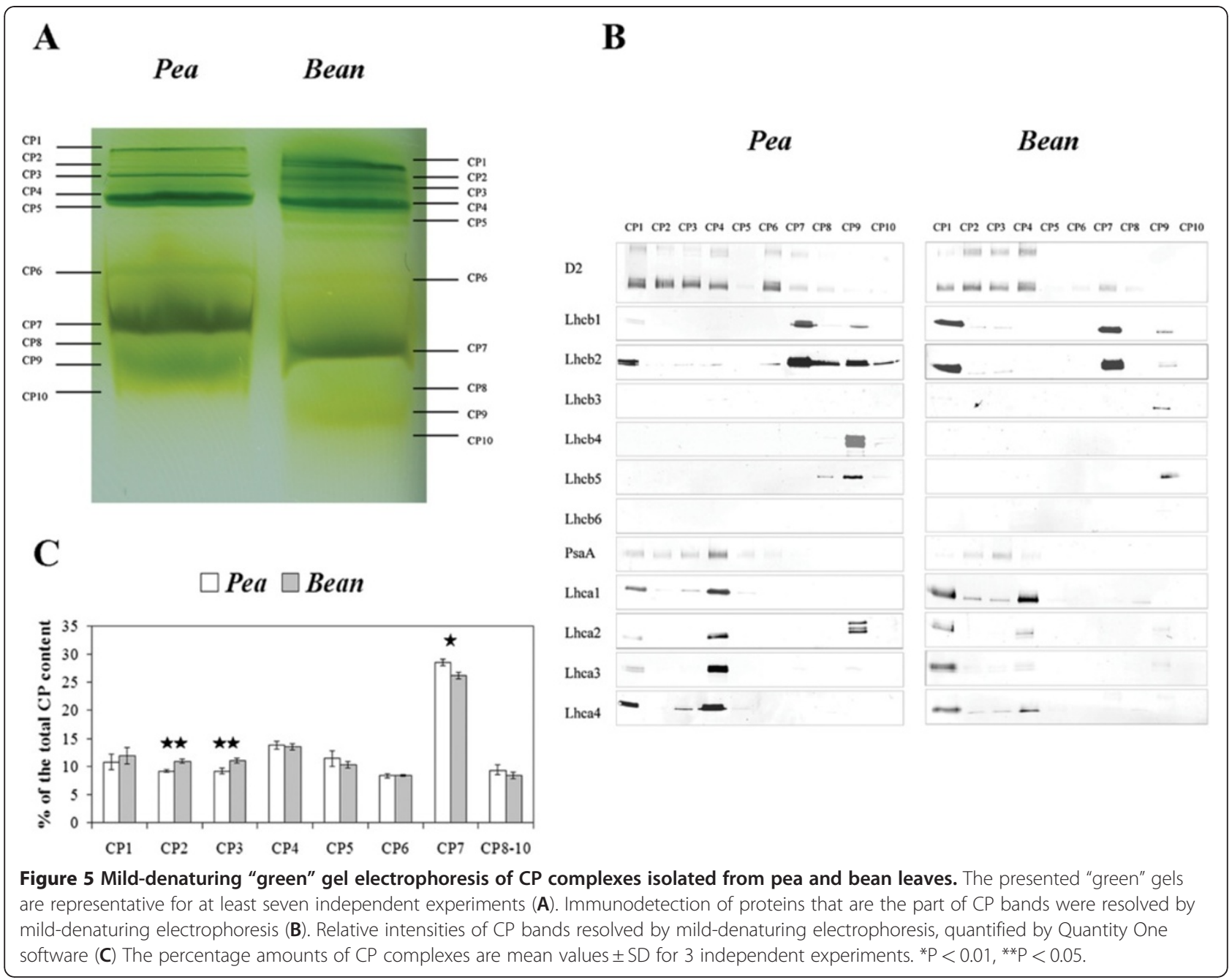

Analysis of the relative composition of the pea and bean thylakoid membranes by low-temperature spectrophotometry

In order to determine the relative contribution of specific complexes to the overall fluorescence pattern in thylakoids isolated from pea and bean leaves, the steady-state fluorescence emission spectra at $77 \mathrm{~K}$ were normalized to the same area (100) under the spectrum (Figure 6A, B). The CP core complexes bind Chl $a$ only [4,8]. The Chl $a / b$ ratio in LHCI was estimated to about 3.5 [10], while in LHCII trimers only to about $1.3[26,27]$. This indicates that the fluorescence emission excited at $412 \mathrm{~nm}$ originated mainly from the PSI and PSII core complexes and only slightly from antenna complexes. On the other hand the emission from LHCII increases significantly under the excitation at $470 \mathrm{~nm}$ and therefore the fluorescence may be related to the abundance of this complex. The spectra of both species exhibited a common maxima at around $682 \mathrm{~nm}, 695 \mathrm{~nm}$ (visible as a shoulder in pea) and $733 \mathrm{~nm}$. However, the ratio between these main bands in pea and bean spectra is different (Figure 6A, B). The thylakoid emission spectrum is highly heterogeneous and might be resolved in some partially overlapping emission bands corresponding to specific CP complexes $[10,28]$. The best Gaussian fit to fluorescence spectra enable to distinguish five components (Additional file 4: Figure S2). The bands at around 682 originated from both trimers and monomers of LHCII and CP43 intrinsic antenna of PSII [29,30]. The bands at 695 correspond to emission from the PSII core and to CP43 intrinsic antenna [30]. Aggregated forms of LHCII, disconnected from PSII reaction centers show an additional band at $703 \mathrm{~nm}$. Two bands in the far red emission region at $734 \mathrm{~nm}$ and $753 \mathrm{~nm}$ are related to the core and antenna of PSI respectively. Thus, integrated intensities of the individual bands at 682 and $695 \mathrm{~nm}$ correspond to LHCII-PSII, while both of fluorescence bands at 734 and 753 were related to LHCI-PSI complexes.

In the spectra excited at $412 \mathrm{~nm}(\mathrm{Chl} a)$ the PSI-LHCI to PSII-LHCII emission ratio was slightly lower in pea 

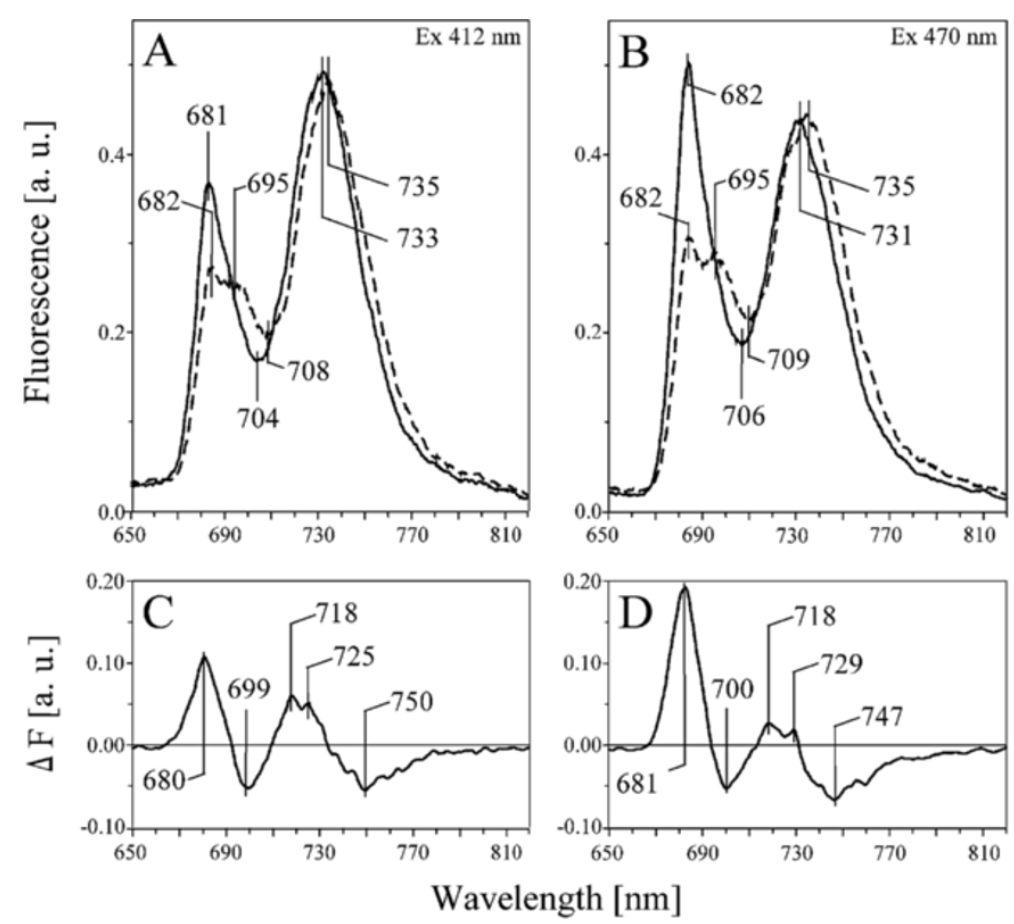

Figure 6 Fluorescence emission spectra at $77 \mathrm{~K}$ of pea and bean thylakoids. Emission spectra excited at 412 (A) and $470 \mathrm{~nm}$ (B) for pea (solid line) and bean (dashed line) thylakoids $\left(10 \mathrm{\mu g} \mathrm{Chl} \mathrm{ml}^{-1}\right)$. Fluorescence emission-difference spectrum pea-minus-bean for samples excited at $412(\mathbf{C})$ and $470 \mathrm{~nm}(\mathbf{D})$. The spectra (A, B) were normalized to the area of 100 under the spectrum, and the difference spectra (C, D) were calculated for the respective excitation spectra. The presented spectra are representative of three separate experiments.

(3.32) than in bean (3.62) thylakoids. Since most of Chl $a$ is bound to core complexes, these data indicate a similar proportion between PSI and PSII core complexes in both species. Under the excitation at $470 \mathrm{~nm}(\mathrm{Chl} b)$ the ratio of (F734 + F753) to (F682 + F695) decreased significantly in pea (2.32) but not in bean (3.20). Furthermore, the ratio F681/F695 following excitations at 412 and $470 \mathrm{~nm}$ increases from 4.5 to 6.0 in pea, whereas is stable in bean (1.1 to 0.96). Because most of Chl $b$ is located in LHCII $[10,26,27]$, it is suggested that higher abundance of LHCII connected with PSII exists in pea than in bean thylakoids. Similar conclusions may be drawn from the pea minus bean differences spectra (Figure 6C, D), where positive band at around $680 \mathrm{~nm}$ attributed to the LHCII complexes $[28,29]$ is observed.

The difference pea - minus - bean spectrum (Figure 6C, D) of the normalized fluorescence emission spectra exhibited a negative band around $700 \mathrm{~nm}$ attributed to the emission from multiaggregated forms of LHCII disconnected from the PSII reaction centers [31,32], suggesting a larger concentration of these complexes in bean. Furthermore, the emission difference spectrum showed a positive band at around $720 \mathrm{~nm}$ and a broad negative band at around $750 \mathrm{~nm}$ (Figure 6C, D), corresponding to the core complex and the antennae of PSI [28]. These data indicate distinct differences in the
LHCI-PSI structure between the two species; probably due to the presence of a number of Lhca1-3 isoforms (cf. Figure 3).

Steady-state electron absorption spectra revealed the properties of pigments bound in CP complexes [33]. The analysis of relative contributions of individual bands in one minus transmission spectra $(100-\mathrm{T})$ at $120 \mathrm{~K}$, normalized to the same area (100) under the spectrum, was performed for pea and bean thylakoids (Figure 7). Pea thylakoids spectrum showed maxima at $437 \mathrm{~nm}(\mathrm{Chl} a)$, $473 \mathrm{~nm}(\mathrm{Chl} b)$ as well as at $678 \mathrm{~nm}\left(\mathrm{Q}_{\mathrm{y}}\right.$ of Chl $\left.a\right)$, whereas the bean thylakoids spectrum revealed redshifted bands for Chl $a$ (440 and $680 \mathrm{~nm}$ ), but not for Chl $b$ (473 and $650 \mathrm{~nm}$ ) (Figure 7A). The difference absorption spectra of pea thylakoid membranes relative to those of bean thylakoids (Figure 7B), exhibited positive bands at Soret and $\mathrm{Q}_{\mathrm{y}}$ regions broad negative bands around 530 and $720 \mathrm{~nm}$ (Figure 7B).

Normalized excitation spectra presented the relative energy transfer from the absorbing pigments to the emitting Chl species reflecting the state of CP complexes [33]. The spectra at $120 \mathrm{~K}(\mathrm{Em} 735 \mathrm{~nm})$ of pea and bean thylakoids revealed typical excitation bands in the Soret region $(400-500 \mathrm{~nm})$ due to light-harvesting by Chl $a$ (436 nm), Chl $b(473 \mathrm{~nm})$, and carotenoid pigments, as well as bands in the red wavelengths solely due to the 

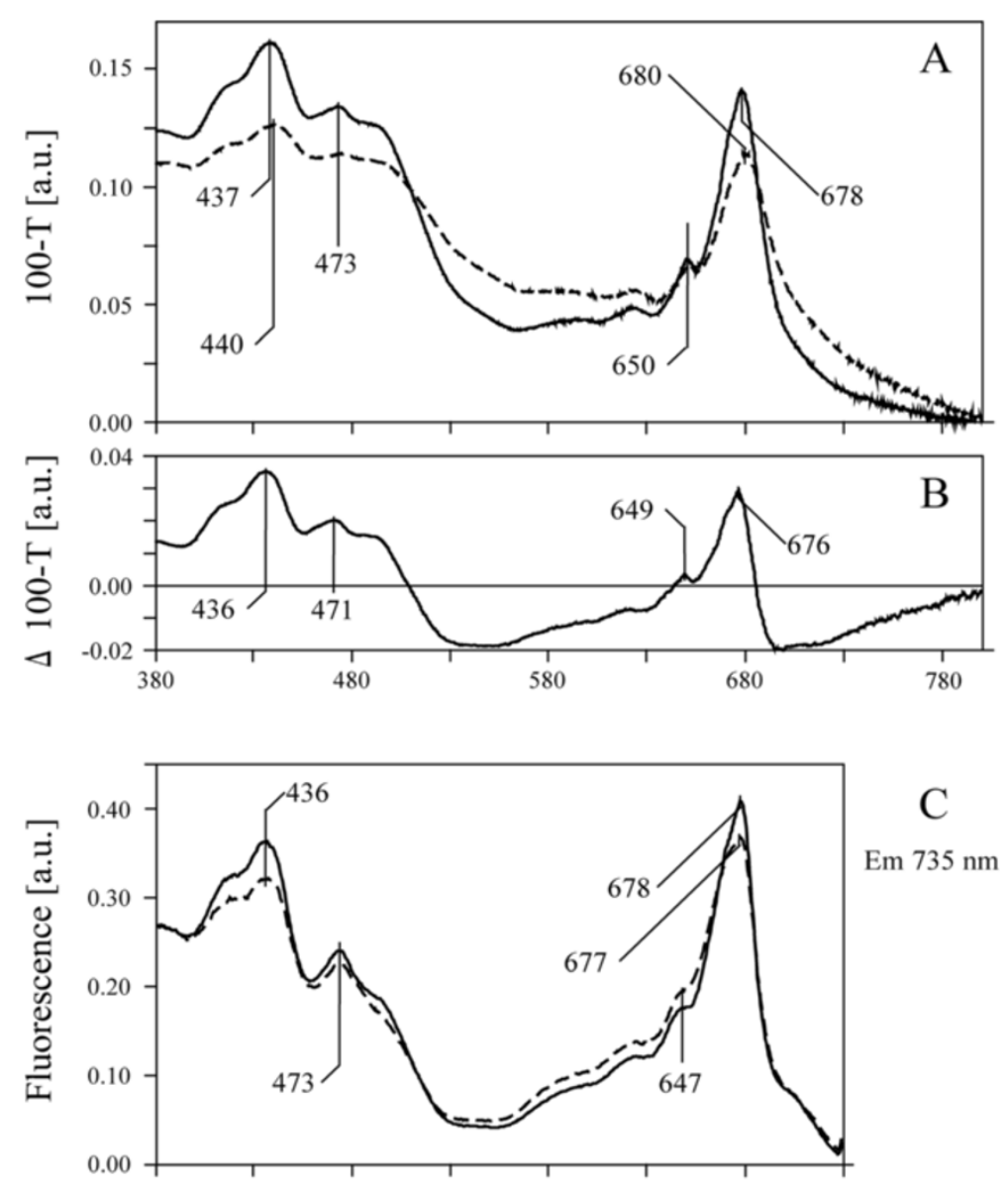

C

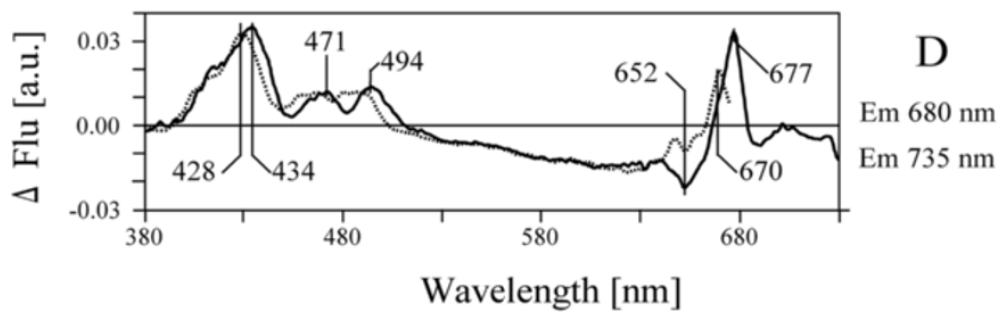

Figure 7 100-T spectra and fluorescence excitation spectra at $120 \mathrm{~K}$ of pea and bean thylakoids. The 100-T (A) and fluorescence

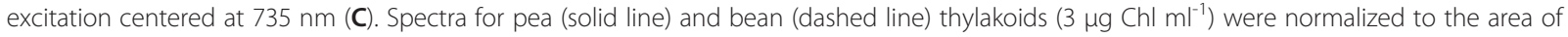
100 under the spectrum. Arithmetic difference spectra pea-minus-bean, were calculated for 100-T spectrum (B) as well as for fluorescence excitation spectra centered at $680 \mathrm{~nm}$ (dotted line) and $735 \mathrm{~nm}$ (solid line) (D).

excitation of Chl $a(677-678 \mathrm{~nm})$ and Chl $b(647 \mathrm{~nm})$ (Figure 7C). Difference excitation spectra between respective pea and bean spectra centered at 680 or $735 \mathrm{~nm}$ showed significant positive bands at around 430,470 and $490 \mathrm{~nm}$ in the Soret region and at $\mathrm{Q}_{y}$ bands of Chl $a$ (Figure 7D).

The shape of main bands in the absorbance and excitation spectra (Figure 7A, C) indicates that they are not affected by the light scattering effect in the Soret and chlorophyll Q regions [33]. Thus, positive bands in the excitation difference spectra (Figure 7D) suggest a more efficient energy transfer from the antennae complexes to both Chl species emitting at 680 (PSII) and $735 \mathrm{~nm}$ (PSI) in pea than in bean thylakoids, probably due to much higher ratio of LHCII to the PSII core (Figure 6). On the other hand, the wide negative bands, present only in the difference absorption spectrum (Figure 7B), are related to light scattering and sieve effects [33-35], probably due to a less regular structure of bean thylakoids (cf. Figures 1 and 2).

\section{Analysis of PSIl functioning based on Chl $a$ fluorescence}

The PSII photochemistry in vivo was tested by measuring the initial $\left(\mathrm{F}_{0}\right)$ and maximum fluorescence $\left(\mathrm{F}_{\mathrm{m}}\right)$ values in 
dark-adapted pea and bean leaves (Figure 8A). The intensities of Chl $a$ fluorescence with open reaction centers $\left(\mathrm{F}_{0}\right)$ were similar in both species, and with closed reaction centers $\left(\mathrm{F}_{\mathrm{m}}\right)$ were slightly higher in pea compared with bean leaves. The absolute values of these parameters can be influenced by optical properties of the leaf. Thus were calculated the variable fluorescence values $\left(\mathrm{F}_{\mathrm{v}}\right)$, that reflect the PSII photochemistry indicated by the redox state of $Q_{A}$, and the $F_{v} / F_{m}$ ratio, that informs about the maximum quantum yield of PSII in the dark-adapted state. The $F_{v} / F_{m}$ ratio did not differ significantly between

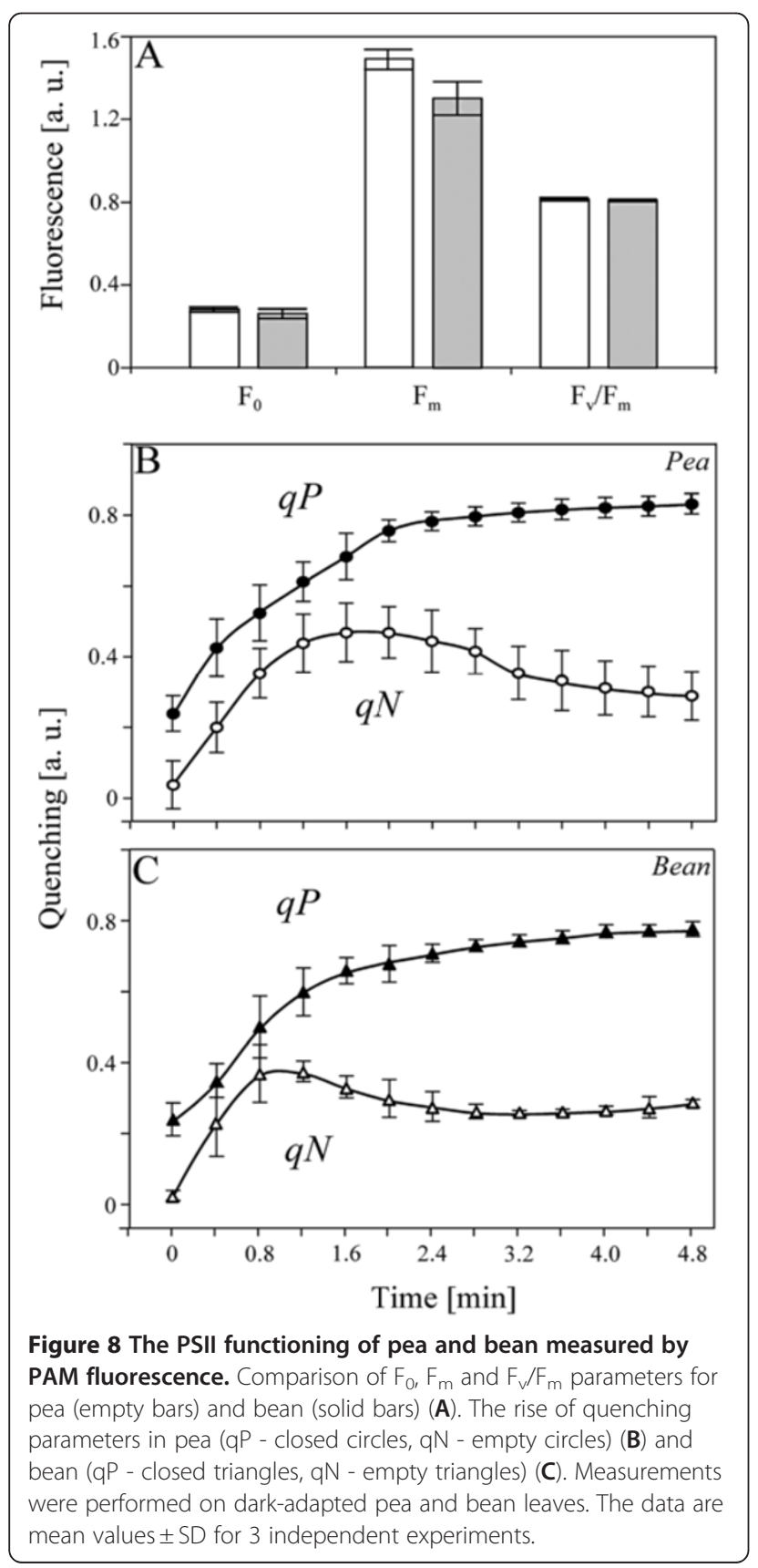

the two species (Figure 8A), indicating the optimization of electron transport and metabolic processes in both plants.

The photochemical quenching coefficient (qP), the PSII efficiency factor, which is non-linearly related to the proportion of open PSII centers ( $\mathrm{Q}_{\mathrm{A}}$ oxidized) at a given light intensity [36], increased similarly in relation to time of illumination (Figure 8B, C). The maximum qP values for pea and bean leaves, reached at saturating light conditions, were estimated at 0.83 and 0.78 , respectively.

The non-photochemical quenching parameter (qN), reflecting the apparent rate constant for non-radiative energy dissipation from PSII and its antennae, revealed a slightly different shape in relation to illumination time (Figure $8 \mathrm{~B}, \mathrm{C}$ ). The maximum $\mathrm{qN}$ values for pea and bean leaves were estimated at 0.47 and 0.37 after five and four consecutive flashes, respectively. Moreover, despite the fact that $\mathrm{qN}$ under saturated light conditions was high (about 0.28), the $\mathrm{qN}$ declined slower in pea than in bean.

The polyphasic fluorescence rises in a time domain from $10 \mu$ s to $1 \mathrm{~s}$ from its origin $(\mathrm{O})$ to its peak (P). The rise has been interpreted, under the strict assumption that photoelectrochemical and photoelectrical events are not involved or ineffective, to reflect the successive filling up of the PSII primary and secondary electron acceptors (Figure 9) [37-41]. Different inflection points of the fluorescence curve have been suggested to correspond to: $J$-the peak concentrations of $\mathrm{Q}_{\mathrm{A}} \mathrm{Q}_{\mathrm{B}}^{-}$and $\mathrm{Q}_{\mathrm{A}}^{-} \mathrm{Q}_{\mathrm{B}}^{-}, \mathrm{I}$ the concentration change of $\mathrm{Q}_{\mathrm{A}}^{-} \mathrm{Q}_{\mathrm{B}}^{2-}$ and $\mathrm{P}-$ the peak concentrations of $\mathrm{Q}_{\mathrm{A}}^{-} \mathrm{Q}_{\mathrm{B}}^{2-}$ and $\mathrm{PQH}_{2}$ [42]. This conceptually means, within this concept, that all reaction centers are open at $\mathrm{O}$ and all are closed at $\mathrm{P}$, if the light pulses

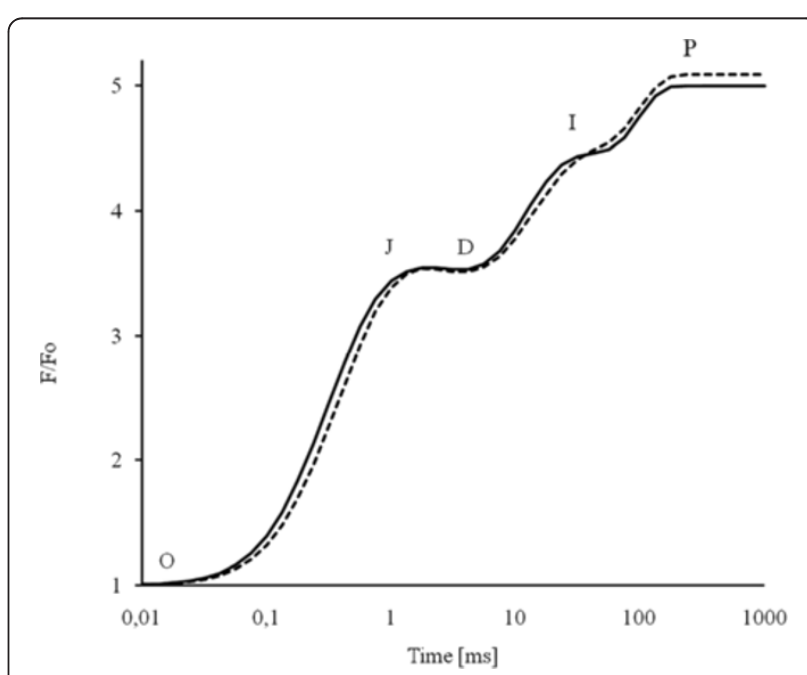

Figure $9 \mathrm{Chl} a$ fluorescence kinetics (OJDIP). Chl $a$ fluorescence induction curves of dark-adapted pea (solid line) and bean (dashed line) leaves. 
are saturating (then $\mathrm{P}=\mathrm{F}_{\mathrm{m}}$ ). The basic pattern for fluorescence kinetics holds for all plants. However, the actual pattern depends, again within the concept, on the number of PSII structural and functional features, such as, the state of water oxidation complex or the redox state of the intersystem electron transport chain [43]. Presented description of fluorescence induction curve distinguished a dip phase (D) between the J and I level and is denoted by the so-called OJDIP rise [41]. The Chl $a$ fluorescence transients of the dark-adapted leaves of pea and bean are shown on the logarithmic scale from $10 \mu \mathrm{s}$ up to $1 \mathrm{~s}$ (Figure 9). Both curves show the typical OJDIP shape (the O, J, I, D and P steps are marked in the plot). After normalization to $\mathrm{F}_{0}=1$, the difference between both curves becomes apparent: (i) the J-, (D-,) and P-levels are somewhat higher in the bean leaf, (ii) the dip (D) is a little more pronounced in pea, and (iii) the steepness of D-I phase is different in both leaf types.

The alternative interpretation of polyphasic OJDIP curve is that the subsequent kinetic phases are associated with the release of photochemical (OJD) and photoelectrochemical quenching (JDI) and of photoelectrical stimulation (IP), respectively [44]. Application of the fluorescence induction algorithm (FIA) to both experimental curves enables the estimation, illustration and comparison of the respective responses of photochemical $\left(\mathrm{F}^{\mathrm{PP}}\right)$, photoelectrochemical $\left(\mathrm{F}^{\mathrm{PE}}\right)$ and photoelectrical $\left(\mathrm{F}^{\mathrm{CET}}\right)$ processes occurring in these time domains (Figure 10).

Release of the photochemical quenching, $\mathrm{F}^{\mathrm{PP}}(\mathrm{t})$, which is the major contributor of the variable fluorescence $F_{v}(t)$ in the O-J-phase (Figure 10A), is associated with about equal maximal variable fluorescence $\mathrm{F}_{\mathrm{v}} / \mathrm{F}_{0}$ of 2.4 and 2.5 in bean and pea, respectively. Initial $\mathrm{F}_{\mathrm{v}}(\mathrm{t})$ kinetics are sigmoidal, indicating equal effect of donor side quenching in both species. The rate of $F_{v}(t)$ is slightly faster in pea, probably due to a somewhat higher antenna size as compared to bean leaves. The release of photoelectrochemical quenching, $\mathrm{F}^{\mathrm{PE}}(\mathrm{t})$, which is the major contributor of the variable fluorescence $\mathrm{Fv}(\mathrm{t})$ in the J-I-phase (Figure 10B), is reflected by a maximal variable fluorescence $\mathrm{F}_{\mathrm{v}} / \mathrm{F}_{0} \sim 1.4$ in both species. The rise kinetics are distinctly different: in bean with nearly exponential kinetics, in pea with a delayed and steeper rise pattern. The photo-electrical stimulation $\mathrm{F}^{\mathrm{CET}}(\mathrm{t})$ causing the final (I$\mathrm{P})$ phase of the variable fluorescence $\mathrm{F}_{\mathrm{v}}(\mathrm{t})$ with maximal $\mathrm{F}_{\mathrm{v}} / \mathrm{F}_{0} \sim 0.54$ and 0.6 in bean and pea, respectively, occurs with a delay of approximately $50 \mathrm{~ms}$ and a steep rise (Figure 10C). The delay and the steepness of $\mathrm{F}^{\mathrm{CET}}(\mathrm{t})$ is somewhat higher in pea. It has been concluded from the FIA-model [44] that an increase in delay and steepness of the fluorescence response during the I-P-phase points to a higher proton buffering capacity at the lumenal side of the CET-driven proton pump. A relation with the size of the granum stack, higher in pea, is suggestive in this respect.

\section{Discussion}

The diversity of chloroplasts membrane system into appressed (stacked) thylakoids and interconnected nonappressed (unstacked) thylakoids is generally described as a consequence of physicochemical interactions between the neighbouring membranes and steric differences between photosystems [5,6,45]. However, complete model of thylakoid membrane network is still under discussion [46,47]. Furthermore, it is not clear what can be the reason of specific arrangements of the thylakoid membranes in various plant species. Our results from CLSM and TEM (Figures 1 and 2) strongly indicate the existence of different arrangements of pea and bean thylakoid membranes. In pea, we showed by CLSM that larger appressed thylakoids are regularly
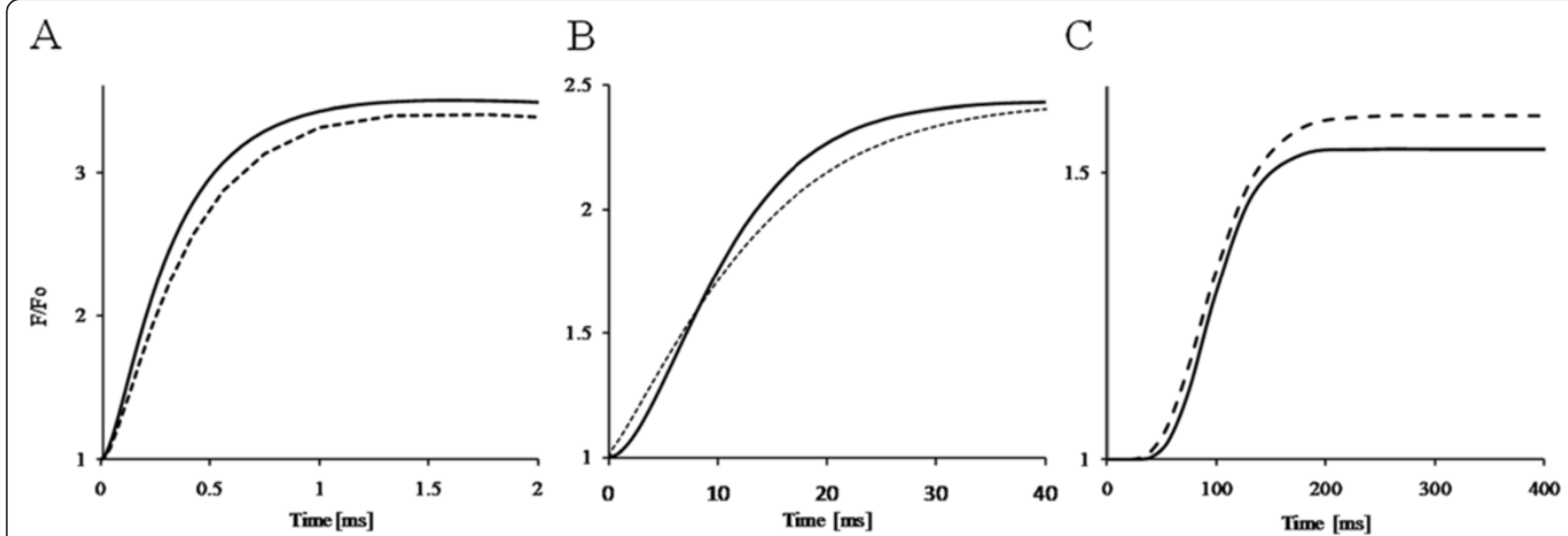

Figure 10 Analysis of OJDIP kinetics curves. Time courses of the release of photochemical (A), photoelectrochemical (B) quenching and of photoelectric fluorescence stimulation $(\mathbf{C})$, respectively in dark-adapted pea (solid lines) and bean leaves (dashed lines) calculated with fluorescence induction algorithm. Curves are on a linear time scale. 
arranged within chloroplasts as uniformly distributed red fluorescent bodies. In contrast, irregularly distributed appressed thylakoid membrane within bean chloroplasts corresponded to smaller and less distinguished fluorescent areas in CLSM images. Recent investigations on selective localization of PSI and PSII fluorescence within chloroplast in situ by Hasegawa et al. [22] demonstrated that the regions of respective fluorescence areas are separated from each other but a significant amount of PSI emission is merged with PSII fluorescence. This means that in our CLSM images (Figure 1 A, B) LHCI-PSI complex might be localized in both dark and red areas, but the LHCII-PSII and LHCII trimers are exclusively restricted to the glowing red bodies.

3D models of pea chloroplast show a distinct and sharp spatial separation of stacked thylakoids from large stromal spaces (Figure 1C, E, Additional file 1: Video S1). The Spatial division of a stroma and thylakoids areas in bean chloroplast is more complicated; stroma spaces are smaller and very irregular (Figure 1D, F, Additional file 2: Video S2). The Spatial layout of Chl fluorescence forms areas that differ in size and spatial orientation (Figure $1 \mathrm{C}-\mathrm{F}$ ), especially in bean chloroplast, where merging of grana and stroma thylakoids is observed (Figure 2D). These 3D models indicate that the spatial arrangement of the thylakoid membranes within chloroplast is more heterogenous, unordered and more diverse between species than could be concluded from single cross-section observed by TEM [48].

The role of LHCII complexes in formation of grana based on investigation of mutants and shade grown plants have been proposed many years ago $[6,16]$. The increase of LHCII abundance in thylakoids or its polyaminylation lead to enhancement of the thylakoid stacking due to the increase of the van der Waals attractive force between the adjacent thylakoid membranes [6,49]. The decrease in the content of one or more Lhcbs proteins leads to the increase of the thylakoids disorder due to the increase of electrostatic and hydratation repulsion $[6,18]$. Furthermore, recent detailed investigations demonstrated that all six Lhcb proteins $[18,50]$ as well as PsbP and PsbQ polypeptides of oxygen evolving complex $[17,51]$ play significant role in the stabilization of LHCII-PSII supercomplexes.

Therefore, to find correlation between the protein composition and the arrangement of pea and bean thylakoids we performed qualitative and quantitative analysis of Lhc and the core proteins as well as the chlorophyllprotein complexes. The immunodetection and MS/MS analysis enabled the identification of seventeen Lhcbs polypeptides in thylakoids of pea and bean (Figure 3A, B). The estimated molecular weights of the Lhcb proteins were similar in pea and bean, but a significant difference in the number and molecular weight of Lhca1-3 isoforms was found (Figure 3C). These observations might indicate that a number of diverse populations of the LHCI-PSI complexes exist both in pea and bean thylakoids. The relative quantitative immunodetection analysis of the selected antennae and the core proteins performed with reference to the total Chl content (Figure 4) provides further evidence that the ratio of the LHCII antennae (Lhcb1) to the PSII core (PsbA) proteins is higher in pea than in bean thylakoids. These data indicate that the diversity in pea and bean chloroplasts ultrastructure (Figures 1 and 2) might result from different quantitative and/or qualitative protein composition (Figures 3 and 4). However, this correlation is probably more complicated due to a complex hierarchical architecture of thylakoids [4].

The basic unit of LHCII-PSII consists of the dimeric form of PSII, two copies of monomeric antennae (Lhcb4, Lhcb5) and two LHCII trimers containing Lhcb1 and Lhcb2 proteins $\left(\mathrm{C}_{2} \mathrm{~S}_{2}\right.$ type $)[4,8] . \mathrm{C}_{2} \mathrm{~S}_{2} \mathrm{M}_{2}$ supercomplex was formed by incorporation of two Lhcb6 and two further trimers [50]. Moreover, up to six LHCII trimers might be associated with PSII dimer $\left(\mathrm{C}_{2} \mathrm{~S}_{2} \mathrm{M}_{2} \mathrm{~L}_{2}\right.$ type) and the aggregates of LHCII trimers $(\mathrm{LHCII})_{\mathrm{n}}$ are detected in grana thylakoids. $\mathrm{C}_{2} \mathrm{~S}_{2} \mathrm{M}_{2}$ supercomplexes are associated in different types of megacomplexes dependent on plant species [4]. Furthermore, $\mathrm{C}_{2} \mathrm{~S}_{2}$ together with LHCII is arranged in stacked thylakoids both in random and in ordered arrangements [3,52]. Moreover, the increased of PSII antenna size and membrane numbers in granum as well as formation of semicrystalline LHCII-PSII arrays are observed in low-light grown plants [53]. The LHCI-PSI complexes in unstacked regions of membranes might bound the LHCII trimers, creating new supercomplexes, but its association in megacomplexes is not established yet [54].

Allen and Staehelin [25] have shown that different species revealed different patterns of green bands in milddenaturing electrophoresis. Moreover, the content of specific bands is related to the abundance of appropriate proteins, as revealed in Arabidopsis mutants [55,56]. We characterized 10 green bands in pea and bean thylakoids. The first five, with high molecular weight, contained polypeptides corresponding to both LHCI-PSI and LHCII-PSII supercomplexes, while the next three bands with lower molecular weights were attributed to LHCIIPSII and LHCII trimers (Figure 5A, B). Mild-denaturing conditions retained the structure of CP supercomplexes and megacomplexes proportionally to accessibility of detergent to particular membrane domains [11,12,25]. Thus, larger amount of green bands related to LHCII-PSII and LHCI-PSI in bean thylakoids (Figure 5) indicates higher density of membranes and stronger interaction between $\mathrm{CP}$ complexes. These observations correlate with previous analysis of the infrared spectrum which 
demonstrates a higher average protein density in bean than in pea thylakoids [57]. Furthermore, the presence of a high molecular green band and a decrease of grana size were observed in psae1-1 mutant of Arabidopsis due to accumulation of stable LHCI-PSI-LHCII supercomplex [55]. Therefore we suggest that higher abundance of the dense megacomplexes influences the thylakoids structure in bean (Figures 1 and 2).

On the other hand, the abundance of green bands related to LHCII, loosely and strongly associated with PSII, is significantly higher in pea thylakoids (Figure 5A, $\mathrm{C})$. Analysis of $77 \mathrm{~K}$ spectra indicate a similar proportion between the PSI and the PSII core complexes in both species, but higher abundance of LHCII in pea thylakoids (Figure 6). Higher ratio of LHCII/PSII core complexes in pea thylakoids is also confirmed by the apoprotein ratio (Figure 4). Furthermore, the difference fluorescence excitation spectra in Soret and chlorophyll $Q$ regions (Figure 7D) indicates a more efficient energy transfer from antennae to the PSII reaction centers in pea than in bean thylakoids. These data suggest that more LHCII trimers are weakly attached to the PSII supercomplex in pea than in bean. Such organization of $\mathrm{CP}$ complexes affects the 3D structure of the whole pea chloroplast, where large condensed areas of stacked thylakoid membranes are observed (Figure 1A, C, E, Additional file 1: Video S1).

A smaller abundance of the LHCII trimers (Figure 5A, C), fluorescence of LHCII antenna (Figure 6B) and smaller relative amounts of Lhcb1 to PsbA apoproteins in bean (Figure 4) in comparison to pea thylakoids were found. The $77 \mathrm{~K}$ difference spectra of bean thylakoids (Figure 6C, D) indicated significant amounts of multiaggregated forms of LHCII which are probably located in separated domains disconnected from PSII [28,32]. These observations suggest that a smaller number of LHCII trimers per PSII reaction center is present in bean than in pea thylakoids.

In spite of the differences in chloroplast structure (Figures 1 and 2), protein and CP composition (Figures 4, 5 and 6) the photosynthetic efficiency represented by $\mathrm{qP}$ is similar in both plants. The parameters $\mathrm{qP}$ and $\mathrm{qN}$ are not directly related: the former is relevant only to the illuminated state of the sample, whereas the latter describes both the light- and dark-adapted states [36]. A slight difference in $\mathrm{qN}$ (Figure 8) and the moment in which the maximum value of $\mathrm{qN}$ is achieved, may suggest distinct reaction to light in the studied plants. These data suggest that bean plants are better adapted to dark-light changes than pea.

Non-photochemical quenching can generally be subdivided into three components: feedback de-excitation (qE), photoinhibition (qI) and state transition (qT) [58]. In the context of the present study, $\mathrm{qE}$ is of interest, since it is the only component connected with changes induced by high-light exposure on a time scale of a few seconds to minutes [59]. Arabidopsis antisense plants lacking most of the Lhcb1 and Lhcb2 proteins exhibited a reduced $\mathrm{qE}$ [60]. However the reduction of $\mathrm{qE}$ is less pronounced in these plants than was reported for intermittent light-grown plants from pea, bean and barley [61]. Moreover, in the $n p q 5$ mutant of Chlamydomonas reinhardtii that lacks specifically the $l$ hcbm 1 gene, $\mathrm{qN}$ was drastically reduced [62]. The simplest interpretation of these data is that the generation of maximum $\mathrm{qE}$ requires a scattered organization of the PSII antenna including major LHCII. Studies of $\mathrm{Mg}^{2+}$ induced stacking of isolated thylakoid membranes of spinach proved that grana stacking is of high importance for the process of overall non-photochemical quenching [63]. Maybe because of that the PSII complexes in the stacked grana membranes posses a larger functional antenna compared with the PSII complexes in the partially and completely unstacked thylakoids [63].

The detailed analysis of polyphasic fluorescence curves (Figure 9) and the comparison of those of the respective underlying processes (Figure 10) suggested a larger functional PSII antenna size $[44,64]$ in pea than in bean thylakoids. Moreover, a different chemical environment, notably a higher number of proton buffering groups, concluded from photoelectrochemical quenching $\left(\mathrm{F}^{\mathrm{PE}}\right)$ and photoelectrical stimulation $\left(\mathrm{F}^{\mathrm{CET}}\right)$ (Figure 10), suggest higher granum stack in pea chloroplasts [44]. Thus, data obtained by both modulated and transient fluorescence (Figures 8, 9 and 10) are in agreement with low temperature spectrophotometry (Figures 6 and 7) and quantitative $\mathrm{CP}$ analysis (Figures 4 and 5).

The size and/or the number of LHCII-PSII complexes play a crucial role in the stabilization of $3 \mathrm{D}$ grana stacks [65]. This relation is seen as large areas for pea and small areas for bean of Chl fluorescence corresponding to grana stacks (Figure 1A, B). Functional analysis confirmed these structural differences (Figure 8, 9 and 10). However, computer models prove that this $3 \mathrm{D}$ relationship is more complicated (Figure 1C, E, D, F) (Additional file 1: Video S1 and Additional file 2: Video S2).

It is known that supercomplexes are organized in different megacomplexes [4] and the vertical structure of thylakoids is determined by the LHCII-PSII and LHCII arrangements $[4,52,66]$. Thus, different distances between the neighbouring membranes in grana stacks, estimated to $21 \mathrm{~nm}$ for pea and $16 \mathrm{~nm}$ for bean (Figure 2C, F) might be a result of a specific arrangement of large and small LHCII-PSII supercomplexes $[4,52,53,66]$. On the other hand, it is hard to explain larger dispersion of Chl fluorescence (Figure 1B) and large irregularity in 3D model for bean chloroplast as compared to pea (Figure 1D-F, Additional file 2: Video 
S2). Probably, a more complicated chloroplast structure might be related to a more complex arrangement of CP complexes (Figures 3 and 5).

Based on spectroscopic analysis and $3 \mathrm{D}$ models we reported recently [57], that the differences in the thylakoid arrangement between pea and bean chloroplasts influence the stacking process in vitro. In pea chloroplasts the increase of magnesium ion concentration changed the degree of membrane appression from wrinkled continuous surface to distinguished stacked areas and a significant increase of the inter-grana area, whereas in bean chloroplasts less pronounced tendencies towards formation of the appressed regions were observed [57].

The protein-protein and lipid-protein interactions play an important role in the formation of the LHCII-PSII megacomplexes in grana thylakoids and influence protein diffusion coefficient $[65,67]$. Recently, based on analysis of infrared spectra, we detected lower protein/lipids ratio in pea than in bean thylakoids [57]. Since about $60 \%$ of total-lipids contribute to the boundary lipids [68], the amounts of the bulk lipid phase is higher in pea thylakoids but the average protein density is higher in bean [57]. Thus, the differences in the arrangement of supercomplexes between species may be a consequence of both lipid and protein content stoichiometry. However, the diversity of protein isoforms (Figure 3) may play a role in interactions between CP complexes [4].

The main goal of our research was to find the relationship between the spatial chloroplast structure detected by CLSM in situ and the arrangements of the CP complexes within the thylakoid membranes. Our 3D computer models of chloroplasts differ from typical chloroplast depictions [48]. We showed that stacked areas are noticeably irregular with variable thickness, merging with each other and are not always parallel to each other.

\section{Conclusions}

Qualitative and quantitative analysis of chlorophyll-protein complexes as well as spectroscopic investigations suggested a close proportion between PSI and PSII core complexes in pea and bean thylakoids, but higher abundance of LHCII antenna in pea. Moreover, higher accumulation of the aggregated form of LHCII in bean thylakoids and distinct differences in the composition of LHCI-PSI between the two species were found. Such composition of membrane induces formation of large stacked domains in pea and many smaller more heterogeneous regions in bean thylakoids. Structural diversity influenced the PSII photochemistry and caused larger functional PSII antenna size in pea, but did not significantly change its photosynthetic efficiency.

We postulate that the differences in chloroplast structure between species are a consequence of quantitative proportions between the individual supercomplexes, their size and arrangement inside membranes.

\section{Methods}

\section{Plant materials and growth conditions}

Pea (Pisum sativum L. cv. Demon) and bean (Phaseolus vulgaris L. $c v$. Eureka) plants (both from PlantiCo Zielonki, 05-082 Babice Stare, Poland) were grown in 3 liter perlite-containing pots in a climate controlled room $\left(22^{\circ} \mathrm{C} / 20^{\circ} \mathrm{C}\right.$ day/night temperature) at a photosynthetic active radiation (PAR) of $200 \mu \mathrm{mol}$ photons $\mathrm{m}^{-2} \mathrm{~s}^{-1}$ during a 16-h photoperiod and a relative humidity of 60 $70 \%$. Plants were fertilized with full Knop's nutrient solution. Fully expanded leaves of 18 and 14 day-old pea and bean, respectively, were harvested 30 minutes after the light had been turned on.

\section{Preparation of thylakoid membranes and of intact chloroplasts}

Thylakoid membranes were isolated by homogenization of pea and bean leaves in a buffered isotonic medium and subsequent osmotic shock as described previously [12]. Intact chloroplasts were isolated in a semi-frozen $20 \mathrm{mM}$ Tricine- $\mathrm{NaOH}$ (pH 7.5) buffer containing $330 \mathrm{mM}$ sorbitol, $15 \mathrm{mM} \mathrm{NaCl}, 4 \mathrm{mM} \mathrm{MgCl}_{2}$ and $40 \mathrm{mM}$ ascorbate by gentle homogenization of pea and bean leaves. After filtration intact chloroplasts were centrifuged at $2000 \mathrm{~g}$ for 3 minutes. Pellet obtained in such a way was very gently resuspended in a small amount of $20 \mathrm{mM}$ HEPES-NaOH (pH 7.0) buffer containing $330 \mathrm{mM}$ sorbitol, $15 \mathrm{mM} \mathrm{NaCl}, 4 \mathrm{mM} \mathrm{MgCl}_{2}$ for further investigation with the help of CLSM. The integrity of at least $80 \%$ of the chloroplasts was determined by ferricyanide reduction before and after the osmotic shock [69]. Chloroplasts with damaged envelope were not a subject of the CLSM analysis. The concentration of chlorophyll and the $\mathrm{Chl} a / \mathrm{Chl} b$ ratio were quantified spectrophotometrically after extraction with $80 \%(\mathrm{v} / \mathrm{v})$ acetone [70].

\section{Confocal laser scanning microscopy and 3D reconstruction}

Isolated intact chloroplasts $\left(30 \mu \mathrm{g} \mathrm{Chl} \mathrm{ml}{ }^{-1}\right)$ were suspended in $20 \mathrm{mM}$ HEPES-NaOH $(\mathrm{pH}$ 7.5) containing $330 \mathrm{mM}$ sorbitol, $6 \%$ (v/v) glycerol, $15 \mathrm{mM} \mathrm{NaCl}$, $4 \mathrm{mM} \mathrm{MgCl}_{2}$ and $30 \mu \mathrm{M}$ 3-(3,4-dichlorophenyl)-1,1dimethylurea. After 10 minutes on ice and in dark incubation the suspension was placed on a poly-L-lysine layer $\left(1 \mathrm{mg} \mathrm{ml}^{-1}\right)$ and immobilized on a microscopic glass. Samples were imaged using Zeiss LSM 510 confocal laser scanning fluorescence microscope equipped with a PlanApo $63 \times$, NA 1.4 objective lens. Excitation was performed at $543 \mathrm{~nm}$ from a helium-neon laser. Fluorescence emission was collected through a $560 \mathrm{~nm}$ 
long pass filter, while the confocal aperture was set at $106 \mu \mathrm{m}$ (1 airy unit). Z-series (94-116 optical slices) of $1024 \times 1024$ pixels and 8 bit images were collected. Images which were not affected by fluorescence quenching due to the light-exposure in microscope were chosen for computer analysis. To improve the signal-to-noise ratio the data stacks were deconvolved using the AutoQuant X2 software (Media Cybernetics Inc. MD, USA). Three-dimensional models of chloroplasts were created by Imaris 6.1 .3 software (Bitplane AG, Switzerland).

\section{Transmission electron microscopy}

Samples of pea and bean leaves were prepared for TEM as described previously [12]. Pieces of about $1-4 \mathrm{~mm}^{2}$ were cut from the middle part of leaves. The material was fixed in $2.5 \%(\mathrm{w} / \mathrm{v})$ glutaraldehyde in $50 \mathrm{mM}$ cacodylate buffer ( $\mathrm{pH}$ 7.4) for $2 \mathrm{~h}$, washed in the buffer and placed in a $2 \%(\mathrm{w} / \mathrm{v})$ osmium tetroxide at $4{ }^{\circ} \mathrm{C}$ in $50 \mathrm{mM}$ cacodylate buffer ( $\mathrm{pH}$ 7.4) for about $12 \mathrm{~h}$. The specimens, dehydrated in a graded acetone series, were embedded in a low viscosity epoxy resin and cut on a Leica UCT ultramicrotome. Sections stained with uranyl acetate and lead citrate were examined with a JEM 1400 electron microscope (JEOL Co. Japan). The length of grana and stroma lamellae as well as the number of membranes per granum were estimated in quadrilateral area of 3 million $\mathrm{nm}^{2}$ using Digital Micrograph v. 3.6.5 demo software (Gatan Inc. CA, USA) for 20 independent images.

\section{SDS-PAGE and immunodetection}

Thylakoid membrane proteins were separated by SDSPAGE in 14-20 \% (w/v) polyacrylamide resolving gels supplemented with $12-17 \%(\mathrm{w} / \mathrm{v})$ sucrose, $0.1 \%(\mathrm{w} / \mathrm{v})$ SDS and $0.42 \mathrm{M}$ Tris- $\mathrm{HCl}$ ( $\mathrm{pH}$ 9.2). Acrylamide linear gradient with the increasing cross-linking ratio was performed with the help of a peristaltic pump. Stacking gels of $6 \%(\mathrm{w} / \mathrm{v})$ were supplemented with $0.1 \%(\mathrm{w} / \mathrm{v})$ SDS and $54 \mathrm{mM}$ Tris- $\mathrm{HCl}(\mathrm{pH}$ 6.1). Thylakoid membranes were solubilized in a $65 \mathrm{mM}$ Tris- $\mathrm{HCl}$ denaturing buffer (pH 9.0) containing 0.29 M sucrose, $0.3 \mathrm{M}$ 2-mercaptoethanol, $2.5 \%(\mathrm{w} / \mathrm{v})$ SDS, $0.1 \%(\mathrm{w} / \mathrm{v})$ bromophenolblue and incubated for 1 minute in $100^{\circ} \mathrm{C}$. Samples containing equal amount of chlorophyll (see Figure legends) were loaded to gel wells and resolved using Hoefer SE 400 electrophoresis cell conducted with a $12.5 \mathrm{mM}$ Tris running buffer $(\mathrm{pH}$ 8.3) containing $96 \mathrm{mM}$ glycine and $0.05 \%$ (w/v) SDS.

After separation, proteins were transferred to a PVDF membrane (Immun-Blot ${ }^{\mathrm{TM}}$, Bio-Rad CA, USA) using an electrophoresis tank filled with a double concentrated running buffer without SDS supplemented with $10 \%$ (v/ v) methanol for $45 \mathrm{~min}$ at $100 \mathrm{~V}$ constant voltage. Next the membranes were blocked for $3 \mathrm{~h}$ in a $20 \mathrm{mM}$ Tris-
$\mathrm{HCl}(\mathrm{pH} 7.5)$ buffer containing $0.5 \mathrm{M} \mathrm{NaCl}$ and $5 \%(\mathrm{w} /$ v) non-fat dry milk and probed with primary polyclonal antibodies with dilutions suggested by the manufacturer (Agrisera, Sweden) for $3 \mathrm{~h}$. The membranes were washed twice for $5 \mathrm{~min}$ in TBST buffer $(20 \mathrm{mM}$ Tris$\mathrm{HCl}, \mathrm{pH} 7.5)$ containing $0.5 \mathrm{M} \mathrm{NaCl}$ and $0.1 \%(\mathrm{v} / \mathrm{v})$ Tween 20 and a secondary anti-rabbit IgG antibody conjugated with alkaline phosphatase (Bio-Rad CA, USA) diluted at 1:3000 in TBST was used for immunodetection. After membrane washing the immunodetection signals were visualised using $p$-nitroblue tetrazolium chloride and 5-bromo-4-chloro-3-indolyl phosphate $p$ toluidine salt (Color Development Solution, Bio-Rad CA, USA). For PsbA protein secondary anti-chicken IgG antibody conjugated with horseradish peroxidase (Sigma, USA) at 1:5000 dilution in TBST was used and developed with 3,3'-diaminobenzidine (DAB substrate, Roche, Switzerland).

\section{Protein identification}

After the electrotransfer the PVDF membrane was cut in a vertical plane into two pieces and one of them was subjected to the immunodetection as described above and the other piece was placed in a staining solution containing $0.1 \%(\mathrm{w} / \mathrm{v})$ Coomassie Blue R-250, $40 \%$ (v/v) methanol, $1 \%(\mathrm{v} / \mathrm{v})$ acetic acid for 1 minute. The membrane was washed in $50 \%(\mathrm{v} / \mathrm{v})$ methanol in water to remove the excess of dye. For protein location on a gel, blotted and stained parts of the PVDF membrane were compared. The identification of proteins was verified by MS/MS analysis as described by [71].

\section{Mild-denaturing "green" electrophoresis}

Chlorophyll-protein complexes were analysed by milddenaturing polyacrylamide gel electrophoresis as described by Allen and Staehelin [25] with some modifications. SDS-depleted $3 \%(\mathrm{w} / \mathrm{v})$ stacking and $8 \%(\mathrm{w} / \mathrm{v})$ resolving polyacrylamide gels supplemented with $10 \%$ (w/v) sucrose and $50 \mathrm{mM}$ glycine were used. Thylakoids membranes $\left(1.26 \mathrm{mg} \mathrm{ml}^{-1}\right)$ were solubilized in $2 \mathrm{mM}$ Tris-maleic acid buffer ( $\mathrm{pH}$ 7.0) containing $10 \%(\mathrm{w} / \mathrm{v})$ sucrose, $0.1 \%(\mathrm{w} / \mathrm{v})$ lithium dodecylsulphate, $0.92 \%(\mathrm{w} /$ v) or $0.65 \%(w / v) n$-decyl- $\beta$-D-maltopyranoside and $n$ octyl- $\beta$-D-glucopyranoside for pea and bean respectively. The detergent concentration used in our experiments corresponded to the most native composition of $\mathrm{CP}$ complexes. When the detergent concentration in the incubation buffer was insufficient, the $\mathrm{CP}$ complexes with big molecular weights did not penetrate the stacking gel and remained in wells. However, in the case of too high detergent concentration in the incubation buffer, the CP complexes were degraded (not shown). After $20 \mathrm{~min}$. dark incubation on ice, samples containing $31.5 \mu \mathrm{g}$ of Chl were loaded to gel wells. The electrophoresis was 
conducted with a $12.5 \mathrm{mM}$ Tris buffer (pH 8.3) containing $96 \mathrm{mM}$ glycine and $0.1 \%(\mathrm{w} / \mathrm{v})$ SDS in MiniProtean3 electrophoresis cell (Bio-Rad CA, USA).

For qualitative analysis the gel bands corresponding to CP complexes previously resolved by the "green" electrophoresis were cut and solubilised in a denaturing buffer, incubated for 10 minutes at $100^{\circ} \mathrm{C}$ and subjected to SDS-PAGE. Polyacrylamide resolving gels of $15 \%(\mathrm{w} / \mathrm{v})$ supplemented with $0.1 \%(w / v)$ SDS, $12 \%(w / v)$ sucrose and $5 \%(\mathrm{w} / \mathrm{v})$ polyacrylamide containing $0.1 \%$ SDS stacking gels were used. The samples were loaded into gel wells, $25 \mu \mathrm{l}$ per well, and electrophoresis was conducted with a running buffer in MiniProtean3 tank. Finally the electrophoresis gels were subjected to the immunodetection procedure as described above.

\section{Gel and blot imaging and quantitative analysis}

The resolved polyacrylamide gels as well as the PVDF membranes following immunodetection were scanned with Microteck ScanMarker 5900 in 48 bit RGB, 1200 $\mathrm{dpi}$, and 8 bit gray scale at $2400 \mathrm{dpi}$ resolution. Relative band intensities were quantified using the Quantity One software (Bio-Rad CA, USA). The proteins' molecular weights were estimated on the basis of the electrophoretical movement rate in comparison with the protein standards (Sigma, USA).

\section{Low fluorescence and absorbance measurements}

Fluorescence emission spectra at $77 \mathrm{~K}$ were recorded using a modified Cary Eclipse (Varian Inc., Australia) fluorescence spectrophotometer where excitation and emission beams were led by optical fibers. Thylakoid samples $\left(10 \mu \mathrm{g} \mathrm{Chl} \mathrm{ml}{ }^{-1}\right)$ were placed in a polytetrafluoroethylene cuvette and submerged in liquid nitrogen. Excitation wavelength was set at 412 or $470 \mathrm{~nm}$, excitation and emission slits at $5 \mathrm{~nm}$ and scans were taken in the range of 600 to $850 \mathrm{~nm}$.

For comparison of absorbance (300-900 nm) and fluorescence excitation spectra (350-675 and 350$735 \mathrm{~nm})$ the samples $\left(3 \mu \mathrm{g} \mathrm{Chl} \mathrm{ml}{ }^{-1}\right)$ were measured in the same temperature $120 \mathrm{~K}$ in $10 \times 10 \mathrm{~mm}$ polymethacrylate cuvettes (Sigma, USA) using a homemade liquid nitrogen cryostat (Institute of Physics, Polish Academy of Sciences, Warsaw). Total optical density of the thylakoid samples did not exceed 0.1 to minimize the innerfilter effects [11]. The temperature was measured directly in a glassy solution by a diode thermometer with the accuracy of $0.5 \mathrm{~K}$. Absorbance and excitation spectra were recorded with the Cary 50 Bio spectrophotometer (Varian Inc., Australia) and the Spex FluoroMax spectrofluorimeter (USA) [57], respectively.

During all measurements the thylakoids were resuspended in $20 \mathrm{mM}$ HEPES-NaOH buffer ( $\mathrm{pH} 7.5$ ) containing $15 \mathrm{mM} \mathrm{NaCl}, 4 \mathrm{mM} \mathrm{MgCl}{ }^{2}$ and $80 \%$ (v/v) glycerol.

\section{Modulated and transient $\mathrm{Chl}$ a fluorescence}

Chlorophyll $a$ fluorescence was measured using a modulated fluorometer (TEACHING-PAM 200, H. Walz $\mathrm{GmbH}, \mathrm{Germany)}$. The maximum $\mathrm{Chl}$ a fluorescence level of 30 min dark-adapted leaves $\left(\mathrm{F}_{\mathrm{m}}\right)$ was determined during a saturating $1 \mathrm{~s}$ flash of $3500 \mu \mathrm{mol} \mathrm{m} \mathrm{m}^{-2} \mathrm{~s}^{-1}$ PAR light. The initial $\mathrm{Chl} a$ fluorescence level of dark-adapted leaves $\left(\mathrm{F}_{0}\right)$ was sensitized with red light of above $1 \mu \mathrm{mol} \mathrm{m} \mathrm{m}^{-2} \mathrm{~s}^{-1}$ PAR. The quantum yield of PSII photochemistry $\left(\mathrm{F}_{\mathrm{v}} / \mathrm{F}_{\mathrm{m}}\right)$ was calculated from the ratio of variable $\left(\mathrm{F}_{\mathrm{v}}=\mathrm{F}_{\mathrm{m}}-\mathrm{F}_{0}\right)$ to the maximum Chl $a$ fluorescence. The photochemical $\left[\mathrm{qP}=\left(\mathrm{F}_{\mathrm{m}}{ }^{\prime}-\mathrm{F}\right) /\left(\mathrm{F}_{\mathrm{m}}{ }^{\prime}-\mathrm{F}_{0}{ }^{\prime}\right)\right]$ and nonphotochemical $\left[\mathrm{qN}=\left(\mathrm{F}_{\mathrm{m}}-\mathrm{F}_{\mathrm{m}}{ }^{\prime}\right) /\left(\mathrm{F}_{\mathrm{m}}-\mathrm{F}_{0}\right)\right]$ quenching coefficients were calculated using the pre-programmed sequence of commands and instrumental settings available with the DA-TEACH software (Protocol No.3 in 'saturation pulse mode'). In this procedure after measuring $\mathrm{F}_{0}$ and $\mathrm{F}_{\mathrm{m}}$, the actinic light $\left(110 \mu \mathrm{mol} \mathrm{m} \mathrm{m}^{-2} \mathrm{~s}^{-1}\right)$ was turned on and the fluorescence was measured. A series of saturation flashes (10 ms duration) were applied at $20 \mathrm{~s}$ intervals (the complete run took $5 \mathrm{~min} 20 \mathrm{~s}$ ), the new $\mathrm{F}_{\mathrm{m}}$ value $\left(\mathrm{F}_{\mathrm{m}}{ }^{\prime}\right)$ was determined and $\mathrm{qP}$ and $\mathrm{qN}$ were calculated.

Chl $a$ fast fluorescence induction curves were recorded in 30 min dark-adapted pea and bean leaves with a PEA Fluorimeter (Hansatech Instruments Ltd, UK) as described previously [12]. The curves were analyzed by fluorescence induction algorithm with the advanced curve fitting method (GOSA) [44,72].

\section{Additional files}

Additional file 1: Video S1. Animated images (rotation $\pm 10^{\circ}$ around $Y$ axis) of chlorophyll fluorescence of pea chloroplast and $3 \mathrm{D}$ reconstruction presented on Figure 1.

Additional file 2: Video S2. Animated images (rotation $\pm 10^{\circ}$ around $Y$ axis) of chlorophyll fluorescence of bean chloroplast and 3D reconstruction presented on Figure 1.

Additional file 3: Figure S1. Protein analysis of pea and bean thylakoid membranes. Full view on SDS-PAGE resolution of thylakoid membrane proteins visualized by staining with Coomassie Blue R-250.

Additional file 4: Figure S2. Gaussian deconvolution of fluorescence emission spectra at $77 \mathrm{~K}$ of pea and bean thylakoids. Pea 412 , Bean 412 samples excited at $412 \mathrm{~nm}$; Pea 470, Bean 470 - samples excited at $470 \mathrm{~nm}$. Spectra were normalized to the area of 100 under the spectrum and subsequently deconvolved into Gaussian bands. The decomposition of fluorescence spectra was performed by using Grams/Al 8.0 spectroscopy Software (Thermo Electron Corporation, USA) programs with 5 Gaussian subbands.

\section{Competing interests}

The authors declare that they have no competing interests.

\section{Acknowledgements}

This work is supported by Polish Ministry of Science and Higher Education Grant N303 01031 0526, chloroplasts modeling was financed by Grant N N303 418533. TEM images were performed in the Laboratory of Electron Microscopy, Nencki Institute of Experimental Biology on JEM 1400 (JEOL Co. Japan) electron microscope. This equipment was installed within the project 
sponsored by the EU Structural Funds: Centre of Advanced Technology BIM - Equipment purchase for the Laboratory of Biological and Medical Imaging.

\section{Author details}

'Department of Plant Anatomy and Cytology, Institute of Plant Experimental Biology and Biotechnology, Faculty of Biology, University of Warsaw, Miecznikowa 1, Warsaw, PL-02-096, Poland. ${ }^{2}$ Department of Metabolic Regulation, Institute of Biochemistry, Faculty of Biology, University of Warsaw, Miecznikowa 1, Warsaw, PL-02-096, Poland. ${ }^{3}$ Department of Biophysics, Institute of Experimental Physics, Faculty of Physics, University of Warsaw, Żwirki i Wigury 93, Warsaw, PL-02-089, Poland. ${ }^{4}$ Australian Animal Health Laboratory, CSIRO Livestock Industries, 5 Portarlington Road Geelong, Victoria, 3220, Australia. ${ }^{5}$ Laboratory of Plant Physiology, Centre for Ecological and Evolutionary Studies (CEES), University of Groningen, P.O. Box 11103, Groningen, 9700 CC, The Netherlands. ${ }^{6}$ Department of Plant Physiology, Wageningen University and Research Centre, Wageningen, 6708 PB, The Netherlands.

\section{Authors' contributions}

$I R, R M, K G, J K-L, B K, B J S, J H V$ performed the experiments and WPM, WJV, KG, $M G$ analyzed the data. MG designed the experiments. $M G, A M, R M, I R, K G$, WJV, JHV, WPM wrote the manuscript. All authors read and approved the final manuscript.

Received: 11 January 2012 Accepted: 10 May 2012

Published: 25 May 2012

\section{References}

1. Anderson JM, Chow WS, De Las Rivas J: Dynamic flexibility in the structure and function of photosystem II in higher plant thylakoid membranes: the grana enigma. Photosynth Res 2008, 98:575-587.

2. Mullineaux CW: Function and evolution of grana. Trends Plant Sci 2005, 10:521-525.

3. Kirchhoff H, Tremmel I, Haase W, Kubitscheck U: Supramolecular Photosystem II organization in grana thylakoid membranes: evidence for a structured arrangement. Biochemistry 2004, 43:9204-9213.

4. Dekker JP, Boekema EJ: Supramolecular organization of thylakoid membrane proteins in green plants. Biochim Biophys Acta 2005, 1706:12-39.

5. Borodich A, Rojdestvenski I, Cottam M, Öquist G: Segregation of the photosystems in thylakoids depends on their size. Biochim Biophys Acta 2003, 1606:73-82.

6. Chow WS, Kim E-H, Horton P, Anderson JM: Granal stacking of thylakoid membranes in higher plant chloroplasts: the physicochemical forces at work and the functional consequences that ensue. Photoch Photobio Sci 2005, 4:1081-1090

7. Danielsson R, Suorsa M, Paakkarinen V, Albertsson P-Å, Styring S, Aro E-M, Mamedov F: Dimeric and Monomeric Organization of Photosystem II. Distribution of five distinct complexes in the different domains of the thylakoid membrane. J Biol Chem 2006, 281:14241-14249.

8. Nield J, Barber J: Refinement of the structural model for the Photosystem II supercomplex of higher plants. Biochim Biophys Acta 2006, 1757:353-361.

9. Mamedov F, Danielsson R, Gadjieva R, Albertsson P- $\AA$, Styring S: EPR characterization of photosystem II from different domains of the thylakoid membrane. Biochemistry 2008, 47:3883-3891.

10. Klimmek F, Ganeteg U, Ihalainen J, van Roon H, Jensen PE, Scheller HV Dekker JP, Jansson S: Structure of the higher plant light harvesting complex I: in vivo characterization and structural interpendence of the Lhca proteins. Biochemistry 2005, 44:3065-3073.

11. Garstka M, Drożak A, Rosiak M, Venema JH, Kierdaszuk B, Simeonova E, van Hasselt PR, Dobrucki J, Mostowska A: Light-dependent reversal of darkchilling induced changes in chloroplast structure and arrangement of chlorophyll-protein complexes in bean thylakoid membranes. Biochim Biophys Acta 2005, 1710:13-23.

12. Garstka M, Venema JH, Rumak I, Gieczewska K, Rosiak M, Kozioł-Lipińska J, Kierdaszuk B, Vredenberg WJ, Mostowska A: Contrasting effect of darkchilling on chloroplast structure and arrangement of chlorophyll-protein complexes in pea and tomato - plants with a different susceptibility to non-freezing temperature. Planta 2007, 226:1165-1181.

13. Allen JF, Forsberg J: Molecular recognition in thylakoid structure and function. Trends Plant Sci 2001, 6:317-326.
14. Chuartzman SG, Nevo R, Shimoni E, Charuvi D, Kiss V, Ohad I, Brumenfeld V, Reich Z: Thylakoid membrane remodeling during state transitions in Arabidopsis. Plant Cell 2008, 20:1029-1039.

15. Tikkanen M, Nurmi M, Suorsa M, Danielsson R, Mamedov F, Styring S, Aro E$M$ : Phosphorylation-dependent regulation of excitation energy distribution between the two photosystems in higher plants. Biochim Biophys Acta 2008, 1777:425-432.

16. Rock ChD, Bowlby NR, Hoffmann-Benning S, Zeevaart JAD: The $a b a$ mutant of Arabidopsis thalina (L.) Heynh. has reduced chlorophyll Fluorescence Yields and reduced thylakoid stacking. Plant Physiol 1992, 100:1796-1801.

17. Ido K, Ifuku K, Yamamoto Y, Ishihara S, Murakami A, Takabe K, Miyake C, Sato F: Knockdown of the PsbP protein does not prevent assembly of the dimeric PSII core complex but impairs accumulation of photosystem II supercomplexes in tobacco. Biochim Biophys Acta 2009, 1787:873-881.

18. Kim E-H, Li X-P, Razeghifard R, Anderson JM, Niyogi KK, Pogson BJ, Chow WS: The multiple roles of light-harvesting chlorophyll a/b-protein complexes define structure and optimize function of Arabidopsis chloroplasts: A study using two chlorophyll b-less mutants. Biochim Biophys Acta 2009, 1787:973-984.

19. Ruban AV, Wentworth M, Yakushevska AE, Andersson J, Lee PJ, Keegstra W, Dekker JP, Boekema EJ, Jansson S, Horton P: Plant lacking the main lightharvesting complex retain photosystem II macro-organization. Nature 2003, 421:648-652.

20. Mehta M, Sarafis V, Critchley C: Thylakoid membrane architecture. Aust J Plant Physiol 1999, 26:709-716.

21. Vacha F, Adamec F, Valenta J, Vacha M: Spatial location of photosystem pigment-protein complexes in thylakoid membranes of chloroplasts of Pisum sativum studied by chlorophyll fluorescence. $J$ Lumin 2007, 122-123:301-303.

22. Hasegawa M, Shiina T, Terazima M, Kumazaki S: Selective photosystems in chloroplasts inside plant leaves observed by near-infrared laserbased fluorescence spectral microscopy. Plant Cell Physiol 2010, 51:225-238

23. Storf S, Stauber EJ, Hippler M, Schmid VHR: Proteomic Analysis of the Photosystem I Light-Harvesting Antenna in Tomato (Lycopersicon esculentum). Biochemistry 2004, 43:9214-9224.

24. Domonkos I, Malec P, Sallai A, Kovács L, Itoh K, Shen G, Ughy B, Bogos B, Samurai I, Kis M, Strzalka K, Wada H, Itoh S, Farkas T, Gombos Z: Phosphatidylglycerol is essential for oligomerization of photosystem I reaction center. Plant Physiol 2004, 134:1471-1478.

25. Allen KD, Staehelin LA: Resolution of 16 to 20 chlorophyll-protein complexes using a low ionic strength native green gel system. Anal Biochem 1991, 194:214-222.

26. Barros T, Royant A, Standfuss J, Dreuw A, Kühlbrandt W: Crystal structure of plant light-harvesting complex shows the active, energy-transmitting state. EMBO J 2009, 28:298-306.

27. Gruszecki WI, Gospodarek M, Grudziński W, Mazur R, Gieczewska K, Garstka M: Light-induced change of configuration of the LHCII-bound xanthophyll (tentatively assigned to violaxanthin): A resonance Raman study. J. Physical Chemistry B 2009, 113:2506-2512.

28. Andreeva A, Stoitchkova K, Busheva M, Apostolova E: Changes in the energy distribution between chlorophyll-protein complexes of thylakoid membranes from pea mutants with modified pigment content I. Changes due to the modified pigment content. J Photochem and Photobiol B 2003, 70:153-162.

29. Ruban AV, Lee PJ, Wentworth M, Young AJ, Horton P: Determination of the Stoichiometry and Strength of Binding of Xanthophylls to the Photosystem II Light Harvesting Complexes. J. Biological Chemistry 1999, 274:10458-10465.

30. Dekker JP, Hassoldt A, Petterson A, van Roon H, Groot ML, van Grondelle R: On the nature of the F695 and F685 emission of Photosystem II In Photosynthesis. In From Light to Biosphere. Volume 2. Edited by Dordrecht MP.: Kluwer; 1995:53-56.

31. Ruban AV, Young AJ, Horton P: Dynamic properties of the minor chlorophyll a/b binding proteins of photosystem II, an in vitro model for photoprotective energy dissipation in the photosynthetic membrane of green plants. Biochemistry 1996, 35:674-678.

32. Šiffel P, Braunová Z: Release and aggregation of the light-harvesting complex in intact leaves subjected to strong $\mathrm{CO}_{2}$ deficit. Photosynth Res 1999, 61:217-226. 
33. Ruban AV, Calkoen F, Kwa SLS, van Grondelle R, Horton P, Dekker JP: Characterisation of LHCII in the aggregated state by linear and circular dichroism spectroscopy. Biochim Biophys Acta 1997, 1321:61-70.

34. Gruszecki Wl, Grudzinski W, Gospodarek M, Patyra M, Maksymiec W: Xanthophyll-induced aggregation of LHCII as a switch between lightharvesting and energy dissipation systems. Biochim Biophys Acta 2006 1757:1504-1511

35. Ruban AV, Res D, Pascal AA, Horton P: Mechanism of $\Delta \mathrm{pH}$-dependent dissipation of absorbed excitation energy by photosynthetic membranes: II. The relationship between aggregation in vitro and $\mathrm{qE}$ in isolated thylakoids. Biochim Biophys Acta 1992, 1102:39-44.

36. Baker NR, Rosenqvist E: Applications of chlorophyll fluorescence can improve crop production strategies: examination of future possibilities. J Exp Bot 2004, 55:1607-1621.

37. Neubauer C, Schreiber U: The polyphasic rise of chlorophyll fluorescence in onset of strong continuous illumination. I. Protein characteristics and partial control by photosysthem II acceptor 1987, 42c:46-54.

38. Strasser RJ, Srivastava A, Govindjee: Polyphasic chlorophyll a fluorescence transient in plants and cyanobacteria. Photochem Photobiol 1995, 61:32-42.

39. Strasser RJ, Tsimilli-Michael M, Srivastava A: Analysis of the Fluorescence Transient. In Chlorophyll fluorescence. In A signature of photosynthesis. Advances in Photosynthesis and Respiration Series. Edited by Papageorgiou GC, Govindjee:: Springer; 2004:321-362.

40. Lazar D: The polyphasic chlorophyll fluorescence rise measured under hight inensity of exciting light. Funct Plant Biol 2001, 33:9-30.

41. Vredenberg WJ: System analysis and photoelectrochemical control of chlorophyll fluorescence in terms of trapping models of photosystem II In a challenging view. In Chlorophyll fluorescence: A signature of photosynthesis. Advances in Photosynthesis and Respiration Series. Edited by Papageorgiou GC, Govindjee.: Springer; 2004:34-195.

42. Zhu X-G, Govindjee, Baker NR, Dde Sturler E, Ort DR, Long SP: Chlorophyll a fluorescence induction kinetics in leaves predicted from a model describing each discrete step of excitation energy and electron transfer associated with Photosystem II. Planta 2005, 223:114-133.

43. Henriques FS: Leaf Chlorophyll Fluorescence: Background and Fundamentals for Plant. Bot Rev 2009, 75:249-270.

44. Vredenberg WJ: Kinetic analysis and mathematical modeling of primary photochemical and photoelectrochemical processes in plant photosystems. Biosystems 2011, 103:138-151.

45. Kim E-H, Chow WS, Horton P, Anderson JM: Entropy-assisted stacking of thylakoid membranes. Biochim Biophys Acta 2005, 1708:187-195.

46. Shimoni E, Rav-Hon O, Ohad I, Brumfeld V, Reich Z: Three-dimensional organization of higher-plant chloroplast thylakoid membranes revealed by electron tomography. Plant Cell 2005, 17:2580-2586.

47. Mustárdy L, Buttle K, Steinbach G, Garab G: The three-dimensional network of the thylakoid membranes in plants: quasihelical model of the granum-stroma assembly. Plant Cell 2008, 20:2552-2557.

48. Albertsson P-Å, Andreasson E: The constant proportion of grana and stroma lamellae in plant chloroplast. Physiol Plantarum 2004, 121:334-342.

49. Ioannidis NE, Ortigosa SM, Veramendi J, Pintó-Marijuan M, Fleck I, Carvajal P, Kotzabasis K, Santos M, Torné JM: Remodeling of tobacco thylakoids by over-expression of maize plastidial transglutaminase. Biochim Biophys Acta 2009, 1787:1215-1222.

50. Caffarri S, Kouŕil R, Kereïche S, Boekema EJ, Croce R: Functional architecture of higher plant photosystem II supercomplexes. EMBO J 2009, 28:3052-3063.

51. Boekema EJ, van Breemen JF, van Roon H, Dekker JP: Conformational changes in photosystem II supercomplexes upon removal of extrinsic subunits. Biochemistry 2000, 39:12907-12915.

52. Kirchhoff $H$, Lenhert $S$, Büchel $C$, Chi L, Nield JP: Probing the Organization of Photosystem II in Photosynthetic Membranes by Atomic Force Microscopy. Biochemistry 2008, 47:431-440.

53. Kirchhoff H, Haase W, Wegner S, Danielsson R, Ackermann R, Albertsson P-A: Low-light-induced formation of semicrystalline Photosystem II arrays in higher plant chloroplast. Biochemistry 2007, 46:11169-11176.

54. Peng L, Shimizu H, Shikanai T: The chloroplast NAD(P)H dehydrogenase complex interacts with Photosystem I in Arabidopsis. J Biol Chem 2008, 283:34873-34879.

55. Pesaresi P, Lunde Ch, Jahns P, Tarantino D, Meurer J, Varotto C, Hirtz R-D Soave C, Scheller HV, Salamini F, Leister D: A stable LHCII-PSI aggregate and suppression of photosynthetic state transition in the psae1-1 mutant of Arabidopsis thaliana. Planta 2002, 215:940-948.

56. Ivanov AG, Hendrickson L, Krol M, Selstam E, Öquist G, Hurry V, Huner NPA: Digalactosyl-diacylglycerol deficiency impairs the capacity for photosynthetic intersystem electron transport and state transitions in Arabidopsis thaliana due to Photosystem I acceptor-side limitations. Plant Cell Physiol 2006, 47:1146-1157.

57. Rumak I, Gieczewska K, Kierdaszuk B, Gruszecki WI, Mostowska A, Mazur R, Garstka M: 3-D modelling of chloroplast structure under $\left(\mathrm{Mg}^{2+}\right)$ magnesium ion treatment. Relationship between thylakoid membrane arrangement and stacking. Biochim Biophys Acta 2010, 1797:1736-1748.

58. Horton P, Ruban AV, Walters RG: Regulation of light harvesting in green plants. Annu Rev Plant Physiol Plant Mol Biol 1996, 47:655-684.

59. Müller $P, L i$ X-P, Niyogi KK: Non-photochemical quenching: a response to excess light energy. Plant Physio/ 2001, 125:1558-1566.

60. Andersson J, Wentworth M, Walters RG, Howard CA, Ruban AV, Horton P, Jansson S: Absence of Lhcb1 and Lhcb2 proteins of the light-harvesting complex of photosystem II - effects on photosynthesis, grana stacking and fitness. Plant J 2003, 35:350-361.

61. Krause GH, Jahns P: Non-photochemical energy dissipation determined by chlorophyll fluorescence quenching: characterization and function. In Chlorophyll fluorescence: A signature of photosynthesis. Advances in Photosynthesis and Respiration Series. Edited by Papageorgiou GC.: Springer; 2004:63-495.

62. Elrad D, Niyogi KK, Grossman AR: A major light-harvesting polypeptide of Photosystem II functions in thermal dissipation. Plant Cell 2002, 14:1801-1816.

63. Goss R, Oroszi S, Wilhelm C: The importance of grana stacking for xanthophyll cycle-dependent NPQ in the thylakoid membranes of higher plants. Physiol Plantarum 2007, 131:496-507.

64. Yusuf MA, Kumar D, Rajwanshi R, Strasser RJ, Tsimilli-Michael M, Govindjee, Sarin NB: Overexpression of $\gamma$-tocopherol methyl transferase gene in transgenic Brassica juncea plants alleviates abiotic stress: Physiological and chlorophyll $a$ fluorescence measurements. Biochim Biophys Acta 2010, 1797:1428-1438.

65. Kirchhoff $\mathrm{H}$ : Molecular crowding and order in photosynthetic membranes. Trends Plant Sci 2008, 13:201-207.

66. Kouril R, Dekker JP, Boekema EJ: Supramolecular organization of photosystem II in green plants. Biochim Biophys Acta 2012, 1817:2-12.

67. Kirchhoff $\mathrm{H}$, Haferkamp S, Allen JF, Epstein DBA, Mullineaux CW: Protein Diffusion and Macromolecular Crowding in Thylakoid Membranes. Plant Physiol 2008, 146:1571-1578.

68. Kirchhoff H, Mukherjee U, Galla H-J: Molecular Architecture of the Thylakoid Membrane: lipid diffusion space for Plastoquinone. Biochemistry 2002, 41:4872-4882.

69. Leegood RC, Malkin R: Isolation of sub-cellular photosynthetic systems. In Photosynthesis energy transduction, a practical approach, Practical Approach Series. Edited by Hipkins MF, Baker NR. Oxford: IRL Press; 1986:9-26.

70. Hipkins MF, Baker NR: Spectroscopy. In Photosynthesis energy transduction, a practical approach, Practical Approach Series. Edited by Hipkins MF, Baker NR. Oxford: IRL Press; 1986:51-101.

71. Shiell BJ, Beddome G, Michalski WP: Mass spectrometric identification and characterisation of the nucleocapsid protein of Menangle virus. J Virol Methods 2002, 102:27-35.

72. Vredenberg WJ, Prasil O: Modeling of chlorophyll a fluorescence kinetics in plant cells. Derivation of a descriptive algorithm. In Photosynthesis in silico. Understanding Complexity from Molecules to Ecosystems. Edited by Laisk A, Nedbal L.: Springer; 2009:125-149.

doi:10.1186/1471-2229-12-72

Cite this article as: Rumak et al:: Correlation between spatial (3D) structure of pea and bean thylakoid membranes and arrangement of chlorophyll-protein complexes. BMC Plant Biology 2012 12:72. 